\title{
Developing a SARS-CoV-2 antigen test using engineered affinity proteins
}

\author{
Seunghyeon Kim ${ }^{a \dagger}, E_{\text {Emma Yee }}^{a \dagger}$, Eric A. Miller ${ }^{a}$, Yining Hao ${ }^{a}$, Dousabel M. Y. Tay ${ }^{a}$, Ki-Joo Sung ${ }^{a}$, Huan \\ Jia $^{b}$, Joseph M. Johnson ${ }^{c}$, Mohsan Saeed ${ }^{d, e}$, Charles R. Mace, Deniz Yüksel Yurt ${ }^{g}$, and Hadley D. Sikes ${ }^{a, b^{*}}$ \\ ${ }^{a}$ Department of Chemical Engineering, Massachusetts Institute of Technology, Cambridge, MA 02139, USA \\ ${ }^{b}$ Antimicrobial Resistance Integrated Research Group, Singapore-MIT Alliance for Research and Technology, \\ 1 CREATE Way, Singapore 138602, Singapore \\ ${ }^{c}$ Quanterix Corporation, Billerica, MA 01821, USA \\ ${ }^{d}$ Department of Biochemistry, Boston University School of Medicine, Boston, MA 02118, USA \\ ${ }^{e}$ National Emerging Infectious Diseases Laboratories (NEIDL), Boston, MA 02188, USA \\ fDepartment of Chemistry, Tufts University, Medford, MA 02155, USA \\ s3M Company, St. Paul, MN 55133, USA
}

†These authors equally contributed to this work.

${ }^{*}$ Corresponding Author:

Prof. Hadley D. Sikes

E-mail: sikes@mit.edu

Keywords: peptides and proteins, library screening, affinity protein, enzyme-linked immunosorbent assays, cellulose 


\section{ABSTRACT}

The ongoing COVID-19 pandemic has clearly established how vital rapid, widely accessible diagnostic tests are in controlling infectious diseases and how difficult and slow it is to scale existing technologies. Here, we demonstrate the use of the rapid affinity pair identification via directed selection (RAPIDS) method to discover multiple affinity pairs for SARS-CoV-2 nucleocapsid protein (N-protein), a biomarker of COVID-19, from in vitro libraries in 10 weeks. The pair with the highest biomarker sensitivity was then integrated into a 10-minute, vertical-flow cellulose paper test. Notably, the as-identified affinity proteins were compatible with a roll-to-roll printing process for large-scale manufacturing of tests. The test achieved $40 \mathrm{pM}$ and $80 \mathrm{pM}$ limits of detection in $1 \times \mathrm{PBS}$ (mock swab) and saliva matrices spiked with cellculture generated SARS-CoV-2 viruses and is also capable of detection of N-protein from characterized clinical swab samples. Hence, this work paves the way towards the mass production of cellulose paperbased assays which can address the shortages faced due to dependence on nitrocellulose and current manufacturing techniques. Further, the results reported herein indicate the promise of RAPIDS and engineered binder proteins for the timely and flexible development of clinically relevant diagnostic tests in response to emerging infectious diseases.

\section{INTRODUCTION}

The COVID-19 pandemic has highlighted the global need for rapid, accessible diagnostic tests for effective disease response and control. ${ }^{1}$ One example of such rapid diagnostic tests (RDTs) is the lateral flow antigen assay, which can provide diagnostic readouts in minutes and is affordable and technologically simple relative to lab-based tests, thus enabling widespread use. ${ }^{2,3}$ However, two significant bottlenecks can limit the rapid development and large-scale manufacturing of these RDTs. Firstly, because nearly all commercialized lateral flow tests utilize nitrocellulose membranes, supply is strained under the unexpectedly large demand in times of pandemic, thus limiting the necessary mass production of these tests for epidemiological control. One solution to this problem is to employ more accessible materials such as cellulose. Cellulose paper has been used as a substrate material for low-cost microfluidic analytical devices because it is inexpensive, widely available, flexible, and compatible with various high-throughput printing methods that could be used to manufacture the devices. ${ }^{3,4}$ Additionally, it has been demonstrated as a platform capable of detecting nanomolar concentrations of biomarkers in clinically relevant matrices. ${ }^{5-8}$ Thus, cellulose-based tests could, in principle, be used alongside nitrocellulose-based tests to ease the supply bottleneck on nitrocellulose and to render RDTs more broadly available. 
Secondly, current processes of identifying sensitive and specific affinity reagent pairs can be a major bottleneck in assay development. Affinity reagents are essential to in vitro diagnostic tests, permitting the specific detection of protein biomarkers of disease in blood, saliva, urine, and other bodily fluids. These tests commonly employ a "sandwich" assay format, in which a substrate-immobilized affinity reagent captures a specific biomarker from the bulk fluid, and a reporter affinity reagent associates a detectable signal with the captured target. This test format spatially concentrates the target from a complex mixture and enhances assay specificity by requiring two independent molecular interactions for signal generation. ${ }^{9}$ However, identifying a complementary pair of affinity reagents with high affinity and specificity for the target and limited cross-reactivity is often a resource- and time-intensive process as demonstrated in traditional hybridoma-based development of antibody pairs. ${ }^{10-15}$

The Rapid Affinity Pair Identification via Directed Selection (RAPIDS) process was previously developed as a more efficient, flexible method for identifying complementary pairs of affinity reagents. ${ }^{10}$ RAPIDS discovers high affinity reagents that function together as a pair in a relevant diagnostic fluid without extensive screening through sub-libraries of purified affinity proteins dominated by clones targeting the same immunodominant epitope. Selective pressure can be exerted to ensure limited cross-reactivity between complementary affinity reagents or with matrix proteins, and for fine discrimination between highly homologous target biomarkers, via counter-selections using off-target proteins. This process is generalizable to many display platforms and scaffold proteins, ${ }^{16-18}$ and has yielded affinity pairs that were demonstrated in a variety of different formats, including yeast surface display, bead-based assays, and wellplate ELISAs, but not yet in a rapid, capillary flow test. ${ }^{10}$ Engineering the thermostable rcSso7d scaffold protein $^{19-21}$ via RAPIDS enabled the selection of three affinity pairs against three different biomarkers (tuberculosis Rv1656, human IL-6, and Zika virus NS1), each within an 18-week development timeline. ${ }^{10}$ In light of the short timeline of RAPIDS and the versatility of rcSso7d, we decided to engineer the rcSso7d protein via RAPIDS to identify high-affinity and target-specific binding pairs against biomarkers of COVID-19 for developing point-of-care antigen tests to control the spread of the disease.

In this work, we developed mass-producible, rapid, cellulose-based COVID-19 antigen tests using RAPIDS-selected affinity pairs. First, RAPIDS was used to select multiple affinity pairs against SARSCoV-2 nucleocapsid protein (N-protein), a biomarker of COVID-19, ${ }^{22-24}$ from in vitro libraries in 10 weeks (Figure 1A). To facilitate the formation of sandwich complexes on cellulose paper, cellulose-binding domain (CBD) fusion constructs were used for rapid, non-covalent, high-density immobilization of the capture binder to cellulose. ${ }^{25}$ The reporter binder, on the other hand, was biotinylated ${ }^{26}$ to permit labeling by streptavidin- or neutravidin-conjugated horseradish peroxidase (HRP) to the sandwich complexes for colorimetric signal amplification via the oxidation of a 3,3', 5,5'-tetramethylbenzidine (TMB) substrate. We 
assessed the performance of selected affinity pairs in paper-based assays and then integrated the pair with the highest diagnostic accuracy into a vertical flow cellulose-based test. These tests were successfully manufactured using roll-to-roll processing, where capture binder fused to CBD (Capture-CBD) followed by blocking solution was machine-deposited onto hydrophilic test zones created by printing a UV-curable resin (Figure 1B). Next, we developed and optimized assays (Figure 1C) for N-protein detection in saliva and swab matrices, the two most commonly used fluids for authorized COVID-19 diagnostic tests, ${ }^{27}$ given their high viral loads. ${ }^{28}$ By testing our assay against recombinant $\mathrm{N}$-protein and tissue culture-generated SARS-CoV-2, as well as against clinical nasopharyngeal swab samples, we demonstrated the ability of our RAPIDS-selected affinity reagents to sensitively and specifically detect COVID-19 antigen in both contrived and clinical samples.

(A) $2 \mathrm{x}$ for distinct epitopes

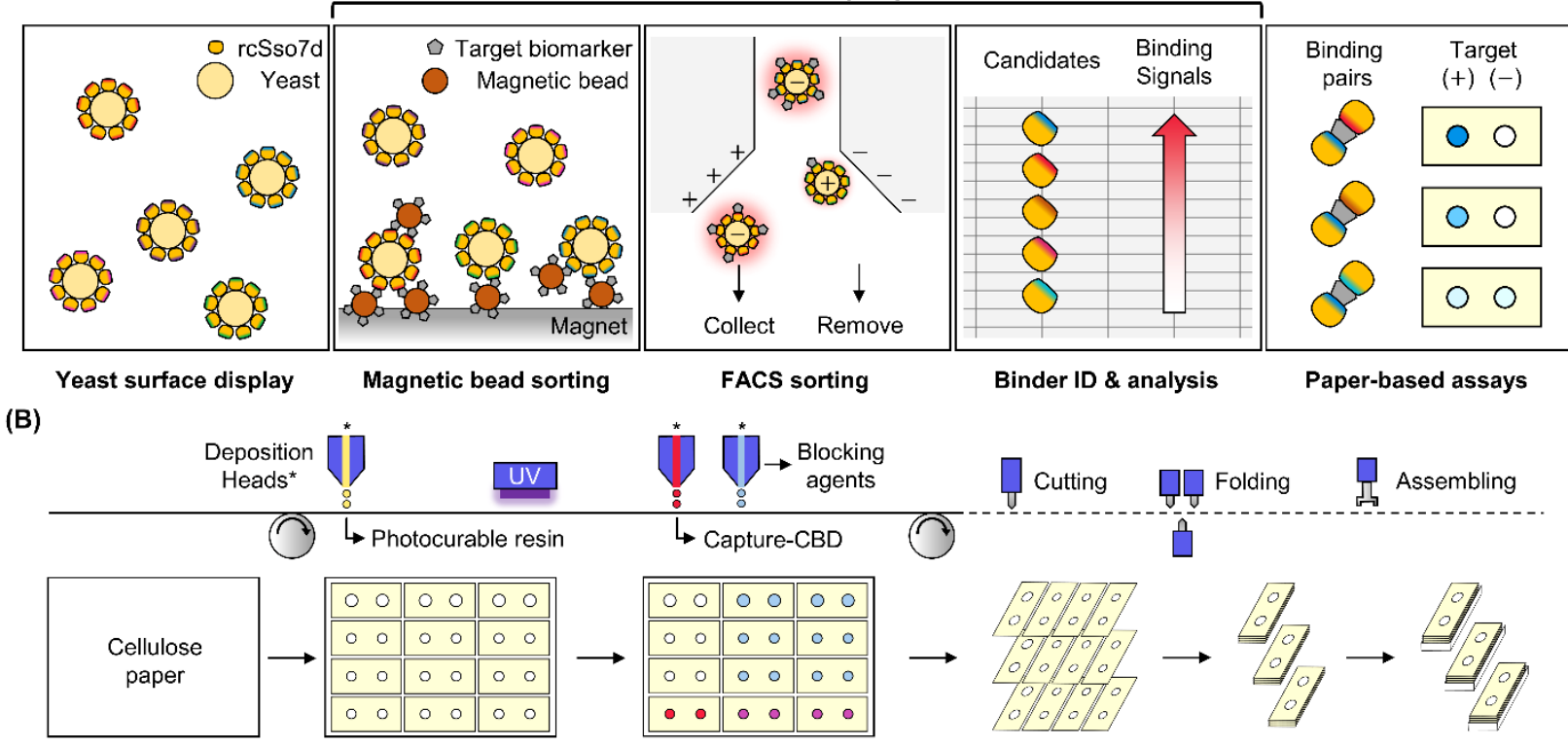

(C)

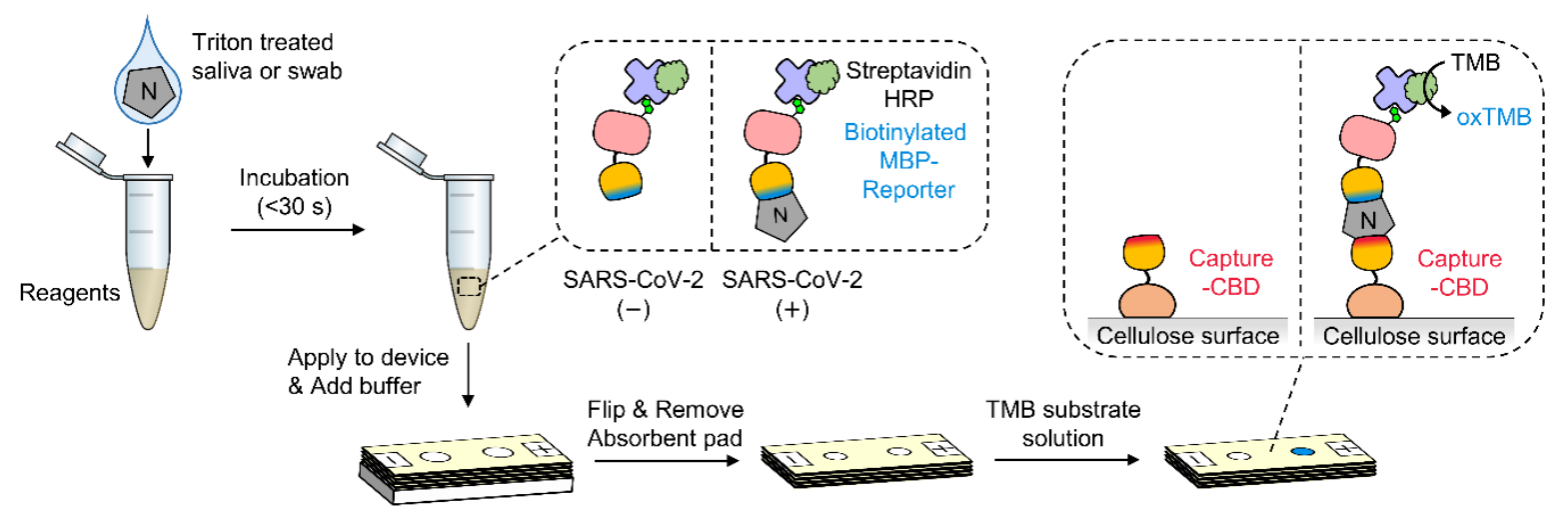

Figure 1. Development of mass-producible, rapid SARS-CoV-2 antigen tests. (A) Workflow for selecting rcSso7d binding pairs against SARS-CoV-2 nucleocapsid protein (N-protein) using the RAPIDS process. 
A yeast surface-displayed library of rcSso7d variants is screened via multiple rounds of magnetic bead sorting and fluorescence activated cell sorting (FACS). Lead clones are assessed via flow cytometry titrations with the target biomarker to rank their binding affinities. A selected binding variant is subcloned, expressed and purified from E. coli, and employed as a reporter reagent in the selection of a capture reagent which simultaneously binds to a distinct target epitope. The selection scheme yields several capture binder candidates, which are tested as binding pairs on paper-based assays. (B) Schematic representation of manufacturing the vertical flow paper-based assays. Cellulose paper is continuously fed from one roller to another as hydrophobic patterns are applied, followed by capture binder genetically fused to cellulosebinding domain (Capture-CBD) on test zones of the fourth layer, and then blocking solution on all hydrophilic zones. The roll of biofunctionalized paper can be cut into four-layer pieces, which are then accordion-folded and fused together with removable wicking pads. Details of manufacturing the assays is provided in Materials and Methods. (C) Schematic of vertical flow paper-based assays for SARS-CoV-2 antigen detection. Human saliva or swab samples treated with Triton X-100 are incubated with reagents including reporter binder fused to biotinylated maltose-binding protein (MBP) and streptavidin- (or neutravidin-) horseradish peroxidase (HRP) conjugate, labeling SARS-CoV-2 N-protein with the enzyme. The mixture of samples and reagents is applied to sample ports, followed by wash buffer. The enzyme labeled N-protein is captured on test zones of the bottom layer by pre-immobilized Capture-CBD. The test zones with the HRP-labeled N-protein generate blue color when TMB substrate solution is added.

\section{RESULTS AND DISCUSSION}


(A)

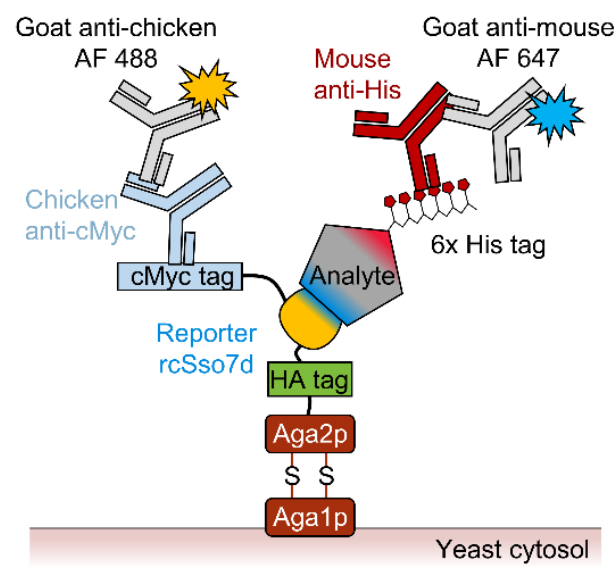

(E)

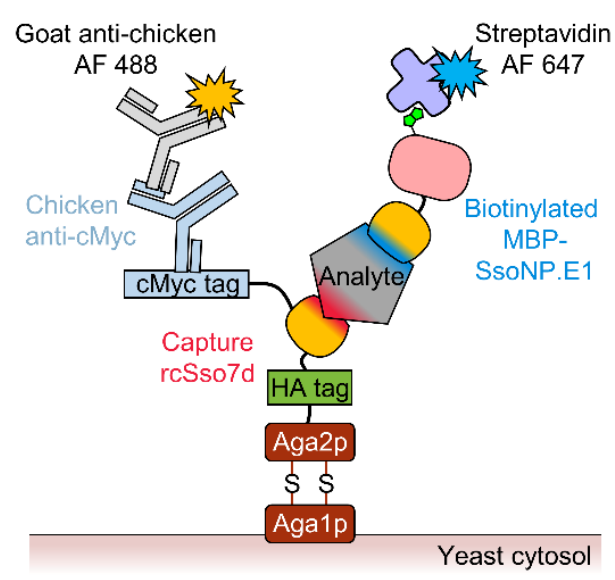

(B)
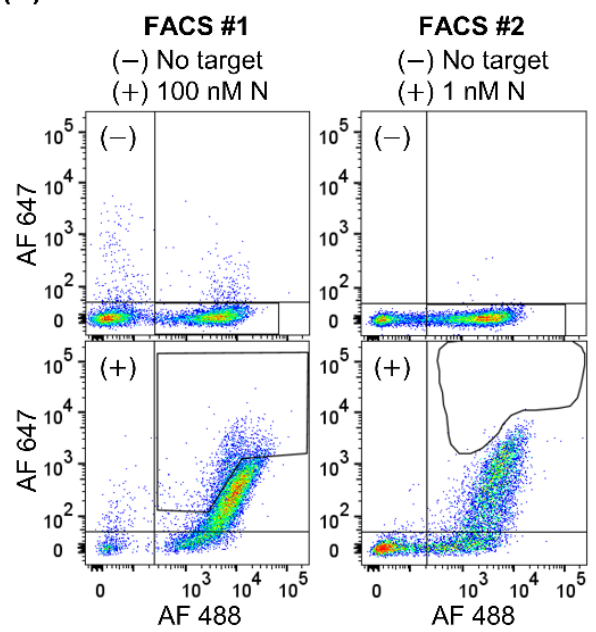

(F)

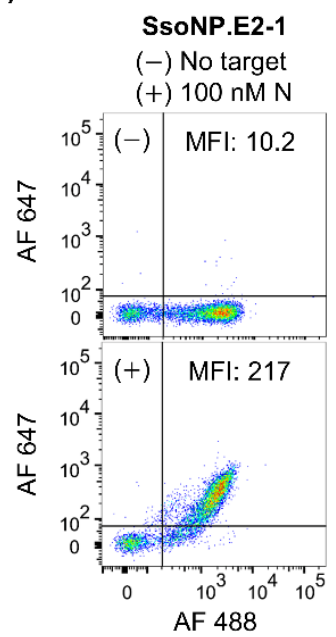

(C)

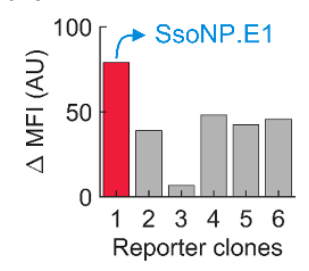

(D)

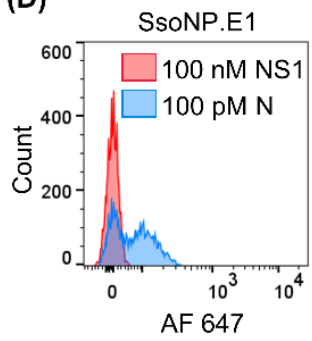

SsoNP.E2-3

(-) No target

(+) $100 \mathrm{nM} \mathrm{N}$

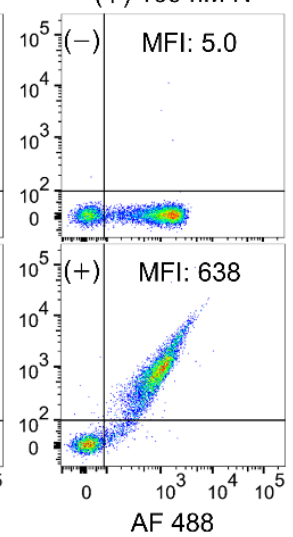

Figure 2. Identification of affinity pairs against SARS-CoV-2 N-protein. (A) Schematic of the protein complex on yeast surface for reporter binder selection in FACS. rcSso7d, flanked by HA/cMyc epitope tags to report display efficiency, is expressed on the yeast surface via genetic fusion to the Aga2p protein, which is released outside of the cell and covalently bonded to Aga 1p species in the cell wall. Target binding signals are generated by the association of fluorescently (AF 647) labeled antibody with the hexahistidine tag of the target molecule. (B) FACS plots for two rounds of reporter binder selection against decreasing concentrations of SARS-CoV-2 N-protein. Gates drawn indicate the sub-population that was retained during sorting. (C) Background-subtracted geometric mean fluorescence intensity calculated from FACS plots when reporter binder candidates are incubated with 100 pM SARS-CoV-2 N-protein. Background signals are measured with $100 \mathrm{nM}$ dengue virus serotype 2 non-structural protein 1 (DENV2 NS1) as a specificity check. (D) FACS histogram showing target-specific binding of selected reporter binder, SsoNP.E1, with the target-positive sample (blue) and the target-negative sample (red). The negative sample included $100 \mathrm{nM}$ DENV2 NS1. (E) Schematic of the protein complex on yeast surface for FACS to discover 
affinity pairs. Yeast cells are fluorescently (AF 647) labeled upon simultaneous binding of the displayed rcSso7d variant to a second epitope (red) in addition to the first epitope bound by the biotinylated MBPSsoNP.E1 reporter (blue). (F) FACS plots showing target-specific binding of biotinylated MBP-SsoNP.E1 $(500 \mathrm{nM})$ and selected capture binders, SsoNP.E2-1, SsoNP.E2-2, and SsoNP.E2-3, in the sandwich assay format without target (top) and with $100 \mathrm{nM}$ SARS-CoV-2 N-protein (bottom). Geometric mean fluorescence intensity (MFI) quantifies the binding signals for each case.

\section{Affinity pair development against SARS-CoV-2 nucleocapsid protein}

We used the RAPIDS process to select rcSso7d-based affinity pairs against SARS-CoV-2 N-protein. First, we identified several reporter rcSso7d variants (Reporter rcSso7d) from a large combinatorial library including over $10^{9}$ distinct clones via standard yeast surface display with positive and negative magnetic bead sorting (MBS) and fluorescence-activated cell sorting (FACS), as described previously. ${ }^{10}$ The rcSso7d-displaying yeast cells were incubated with recombinant $\mathrm{N}$-protein and labeled with fluorescent reagents to probe display efficiency and target-specific binding activity (Figures $2 \mathbf{A}$ and S1). To enrich high-affinity specific binders, we depleted non-specific binding variants via negative sorting and captured the small fraction of specific binding variants. We repeated this selection process over multiple rounds of FACS with decreasing N-protein concentration and capture percentage (Figure 2B). Then, we identified six lead clones within the enriched population (Table S1) and assessed their specific binding activity to Nprotein in the yeast-surface display format (Figures 2C and S2). The first clone showed the highest binding signals among the reporter binder candidates and low cross-reactivity (Figure 2D), so we selected the clone as the first binder in the affinity pair (SsoNP.E1) and integrated this binder into a fusion construct with in vivo-biotinylated MBP; referred to as biotinylated MBP-SsoNP.E1 (Table S3).

To identify rcSso7d variants that pair with the reporter clone and can serve as capture reagents (Capture rcSso7d), we applied an epitope-specific selective pressure to ensure that the selected affinity reagents target non-overlapping epitopes. Instead of hexahistidine labeling in FACS, we employed biotinylated MBP-SsoNP.E1 and streptavidin-AF 647 as labeling reagents during the selection of affinity pairs (Figure 2E). In this scheme, fluorescence signals are detected when simultaneous binding occurs between rcSso $7 \mathrm{~d}$ on yeast surface, unlabeled N-protein, and the biotinylated MBP-SsoNP.E1 with streptavidin-AF 647, allowing the selection process to enrich capture binders targeting distinct epitopes. The yeast sub-library of clones that bind the N-protein was sorted via three rounds of FACS with decreasing proportion of clones retained and decreasing concentrations of the N-protein and the biotinylated reporter binder to increase selection stringency and minimize enrichment of affinity reagents that cross-react with biotinylated MBPSsoNP.E1 (Figure S3). Out of curiosity, we also selected capture binder clones against baculovirus- 
produced SARS-CoV-1 N-protein (Figure S4) because SARS-CoV-2 N-protein expressed in insect cells was not commercially available at the moment and high degree of homology was expected between SARSCoV-2 and SARS-CoV-1 N-proteins. ${ }^{29}$ After the final rounds of FACS, we identified multiple clones from the yeast sub-library, selected three high-affinity clones (SsoNP.E2-1, E2-2, and E2-3) with low nonspecific binding when paired with biotinylated MBP-SsoNP.E1 (Table S2 and Figure 2F), and integrated them into fusion constructs with CBD.

(A)

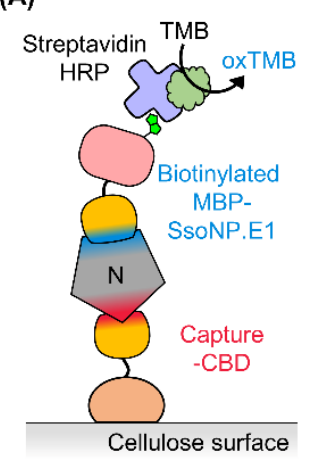

(B)

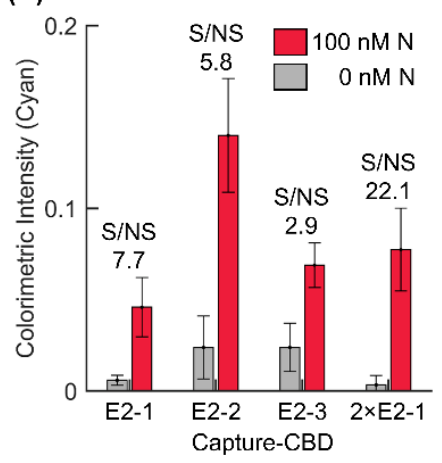

(C)

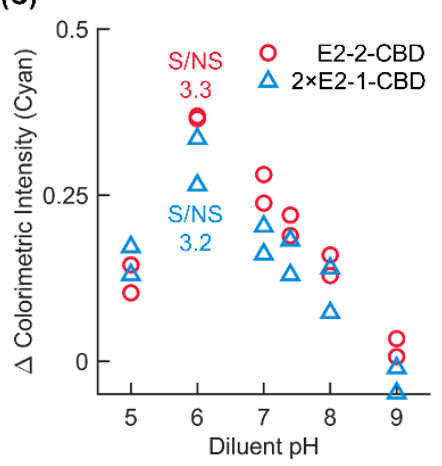

(D)

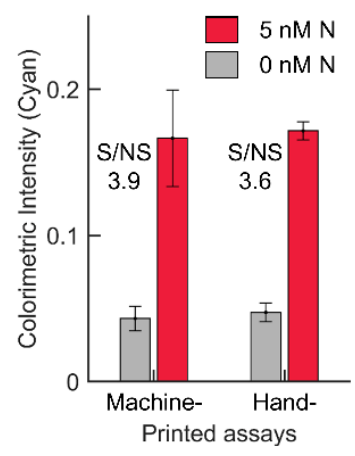

(E)

\begin{tabular}{ccc}
\hline Selected binders & SsoNP.E1 & SsoNP.E2 \\
\hline Binding face shorthand tag & IRGWSWYAY & NGWIDDIIA \\
Fusion partner & BA-MBP & CBD \\
$\mathrm{K}_{\mathrm{d}}(\mathrm{M})$ & $3.24 \times 10^{-9}$ & $4.42 \times 10^{-9}$ \\
$k_{\text {on }}\left(\mathrm{M}^{-1} \mathrm{~s}^{-1}\right)$ & $3.59 \times 10^{4}$ & $3.94 \times 10^{4}$ \\
$k_{\text {off }}\left(\mathrm{s}^{-1}\right)$ & $1.16 \times 10^{-4}$ & $1.73 \times 10^{-4}$ \\
\hline
\end{tabular}

(F)

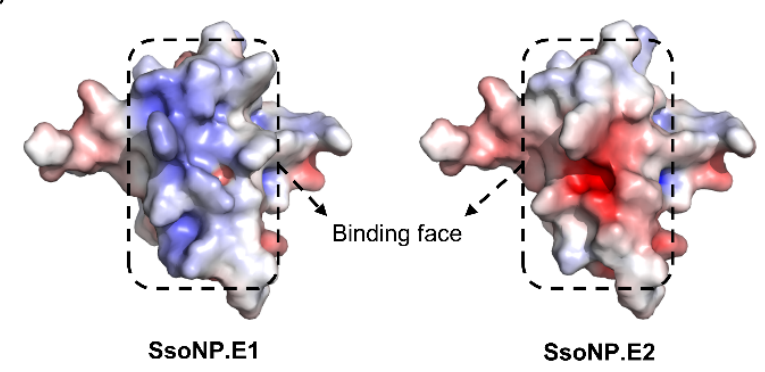

Figure 3. Testing selected binding pairs on paper-based assays. (A) Schematic of the protein complex on test zones of paper-based assays in the presence of SARS-CoV-2 N-protein. CBD-fused capture binder (Capture-CBD) candidates are pre-immobilized on test zones and exposed to the mixture of sample and reagent solution including biotinylated MBP-SsoNP.E1 and HRP-conjugated streptavidin. The desired complex (above) is formed in the presence of the target biomarker, producing blue color as TMB substrate solution is added. Otherwise, the reagents are washed away, leaving only Capture-CBD on test zones. (B) Screening of the selected binding pairs on single-layer paper-based assays. Details of this assay is provided in Supporting Information. Three different capture binder clones (E2-1, E2-2, and E2-3) and a dimer of E21 were fused to CBD and formed pairs with biotinylated MBP-SsoNP.E1. The plot shows target-specific signals (S, red) and non-specific signals (NS, gray) in cyan intensity and the ratio of S to NS. Each bar graph consists of an average of four replicates, and error bars represent standard deviation. (C) Final round of binding pair selection in vertical flow paper-based assays with optimizing diluent $\mathrm{pH}$. Target-specific signals (S, $100 \mathrm{nM} \mathrm{N-protein)} \mathrm{and} \mathrm{non-specific} \mathrm{signals} \mathrm{(NS,} 0 \mathrm{nM}$ N-protein) are quantified as cyan 
colorimetric intensity at various $\mathrm{pH}$. Both binding pairs showed optimal binding signals at $\mathrm{pH}$ 6, but E2-2CBD achieved slightly better sensitivity than $2 \times$ E2-1-CBD while maintaining similar ratio of S to NS. (D) Comparing test performance of machine-printed and hand-printed assays. Both assays produce similar target-specific signals (S, $5 \mathrm{nM} \mathrm{N}$-protein) and non-specific signals (NS, $0 \mathrm{nM} \mathrm{N}$-protein) and their ratio (S/NS). These results indicate that the capture reagent and blocking solution preserve their activity after the automated manufacturing process. (E) Binding face amino acid sequences of the selected binders and their biophysical constants in fused forms. (F) The electrostatic surface potential of the selected binders (SsoNP.E1 and SsoNP.E2). Red and blue colors indicate negative and positive potential, respectively. The binding sites for $\mathrm{N}$-protein are highlighted in dashed rectangles and labeled.

\section{Binding pair assessment on cellulose paper}

The binding pairs selected through RAPIDS process demonstrated complementary binding, but an additional assessment on cellulose paper was conducted to ensure optimal functionality with the final assay components such as cellulose and streptavidin-HRP. For this test, each capture binder-CBD fusion construct was immobilized on cellulose paper and incubated with sample solution treated with reagents including biotinylated MBP-SsoNP.E1 and streptavidin-HRP. If the sample includes SARS-CoV-2 N-protein, the HRP enzyme is specifically immobilized within the cellulose test zone, generating blue color as TMB substrate solution is added (Figure 3A). Using single-layer paper-based assays created with solid wax ink (as described in Supporting Information), we evaluated four different Capture-CBD paired with SsoNP.E1, selecting SsoNP.E2-2-CBD and 2×SsoNP.E2-1-CBD (two E2-1 binders linked together) for giving the highest specific signal and the highest ratio of specific signals to non-specific signals, respectively (Figure 3B).

Next, the two binders were assessed with vertical flow paper-based assays at various diluent $\mathrm{pH}$, and the SsoNP.E2-2-CBD was selected for its superior specific signals at optimal pH 6 (Figure 3C). This CBDfused capture affinity reagent will henceforth be referred to as SsoNP.E2-CBD (Table S3). We verified the purity of the best complementary affinity pair with respective fusion proteins via SDS-PAGE (Figure S5), sequenced the binders, and measured the binding kinetic parameters $\left(\mathrm{K}_{\mathrm{d}}, k_{o n}\right.$, and $\left.k_{o f f}\right)$ for the engineered affinity proteins (Figures 3E and S6). Notably, the binding face amino acid sequences of the selected binders are distinct (Figure 3E) and the electrostatic potential surfaces display opposite charges on their binding surface (Figure 3F). These results clearly demonstrate that the two binders target different epitopes of SARS-CoV-2 N-protein, reconfirming that the RAPIDS technique can quickly identify complementary pairs of affinity reagents. 
Finally, we examined if the SsoNP.E2-CBD could maintain its binding activity after it was printed on test zones via a roll-to-roll process. Colorimetric readout from tests where SsoNP.E2-CBD and blocking solution were manually applied using pipette was comparable to the signals from tests where the reagents were machine-printed in the mass-production setting (Figure 3D). Strong agreement between assays produced via these distinct manufacturing approaches clearly demonstrates the compatibility of the selected SsoNP.E2-CBD with mass-manufacturing processes. Together with low-cost, high-yield production (unoptimized yields of $58.5 \mathrm{mg}$ biotinylated MBP-SsoNP.E1 and $150 \mathrm{mg}$ SsoNP.E2-CBD from $500 \mathrm{~mL}$ culture) of the affinity pair (Table S4), we believe that the proposed rapid SARS-CoV-2 antigen test has great potential to be rapidly produced at massive scale.

\section{Design of cellulose paper-based microfluidic assay and optimization}

As shown in Figure 1B, our vertical flow assay design features a removable absorbent pad that covers a test zone at the end of the vertical flow channel and the lack of lateral flow channel. This design was selected for a rapid and sensitive SARS-CoV-2 N-protein assay after assessing several paper-based microfluidic device designs (Figure S7). To achieve high sensitivity, it is desirable to give affinity reagents sufficient time to interact with target biomarkers to maximize labeling and capture, while minimizing non-specific binding and non-productive loss of reagents to the paper hold-up volume. Designs with lateral flow channels were subject to high non-specific binding signals because of low linear flow velocity at the lateralto-vertical flow channel junction, as indicated by the accumulation of reporting enzyme due to non-specific interactions with cellulose (Figure S8). Thus, the lateral flow channels were removed to reduce nonspecific binding signals within the assay. The use of a test zone in the bottom-most layer proved advantageous despite requiring the removal of the wicking pad to check the colorimetric readout (Figure S8). When capture binder was immobilized on the sample ports of the top layer, wherein the sample application port also functions as the test readout zone, the assays produced highly variable colorimetric signals due to the spatially irregular flow rates across the test zone caused by non-uniform pore size and pore-blocking by large particles in sample. However, in our final vertical flow assay design, wherein the test zone is located in the bottom-most paper layer, large particles in the sample are filtered out in the course of flowing through multiple layers. We hypothesize that this likely allows spatial non-uniformity to equalize by the time the filtrate interacts with capture binders on the test zone, improving consistency of the signals.

After selecting the vertical flow design, we optimized assay conditions for both human saliva (Figures S9-S12) and mock nasopharyngeal swab samples (Figures S13-S15). As presented in Figure 3C, optimal $\mathrm{pH}$ for the assay was $\mathrm{pH}$, so we employed $\mathrm{pH} 6$ phosphate buffer for diluent and wash buffer in saliva assays, and optimized concentrations of phosphate, salt, blocker protein, and detergent. Then, we optimized 
blocking solution on paper and concentrations of the affinity pair. For the simulated swab samples, we spiked SARS-CoV-2 N-protein into $1 \times \mathrm{PBS}$, and we used concentrated reagent solution including neutravidin-HRP instead of streptavidin-HRP to improve the assay sensitivity.

(A)

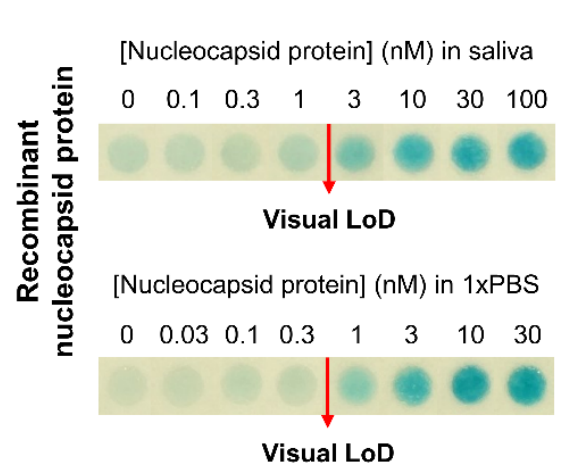

(D)

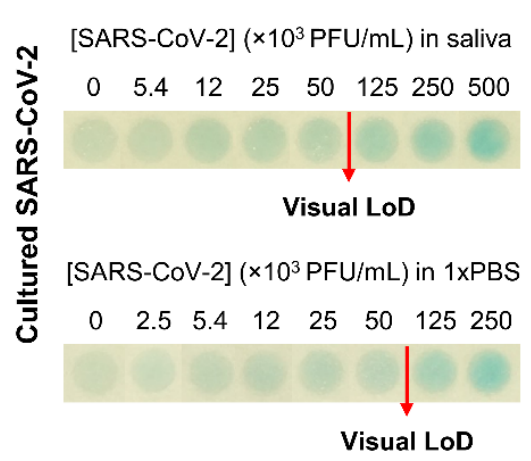

(B)

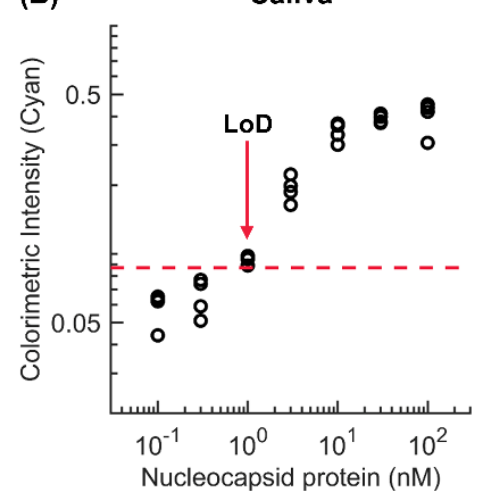

Saliva

(E)

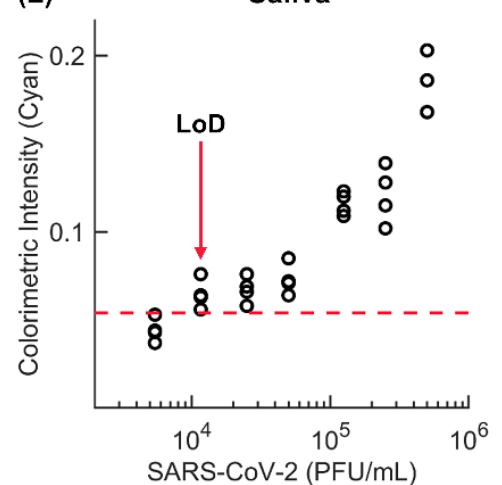

(C)

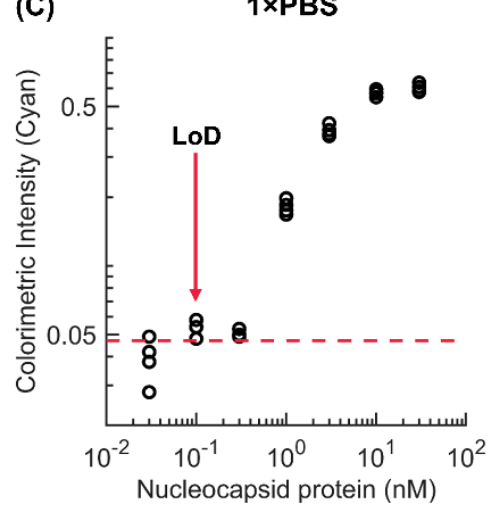

(F)

$1 \times$ PBS

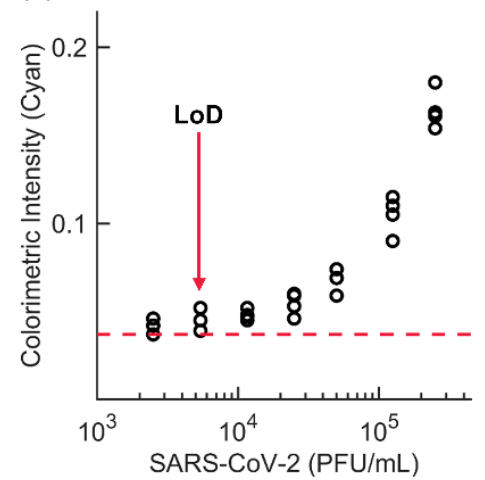

Figure 4. Detection of recombinant SARS-CoV-2 N-protein or cultured SARS-CoV-2 spiked into saliva and $1 \times$ PBS. (A) Representative images of the assay results with recombinant SARS-CoV-2 N-protein spiked into saliva and $1 \times$ PBS. Replicates are available in Figure S16. (B, C) Dose response curve for recombinant SARS-CoV-2 N-protein in saliva (B) and $1 \times$ PBS (C). Colorimetric intensity (Cyan) values were calculated using ImageJ. ${ }^{30}$ The red dotted line $(\mathrm{Neg}+3 \sigma)$ represents the mean cyan intensity (Neg) of $0 \mathrm{nM}$ samples plus three times their standard deviation $(\sigma)$. LoDs in saliva $(1 \mathrm{nM})$ and in $1 \times \operatorname{PBS}(0.1 \mathrm{nM})$ were calculated as the lowest $\mathrm{N}$-protein concentrations that provided signals above the lines. (D) Representative images of the assay results with cultured SARS-CoV-2 spiked into saliva and $1 \times$ PBS. Replicates are available in Figure S17. (E, F) Dose response curve for cultured SARS-CoV-2 in saliva (E) and $1 \times \mathrm{PBS}(\mathrm{F})$. The red dotted line represents $\mathrm{Neg}+3 \sigma$ as described above. LoDs in saliva $\left(1.2 \times 10^{4} \mathrm{PFU} / \mathrm{mL}\right)$ and in $1 \times \mathrm{PBS}\left(5.4 \times 10^{3} \mathrm{PFU} / \mathrm{mL}\right)$ were calculated as the lowest $\mathrm{N}$-protein concentrations that provided signals above the lines. 


\section{Assessing limit of detection}

With the optimized assay conditions, we assessed performance of the SARS-CoV-2 N-protein test by challenging it with human saliva and $1 \times$ PBS (as mock swab) samples spiked with various concentrations of recombinant $\mathrm{N}$-protein to determine the limit of detection (LoD), which is defined as three standard deviations greater than the mean negative control signal. As demonstrated in Figure 4A, it was possible to visually detect $>3 \mathrm{nMN}$-protein in saliva and $>1 \mathrm{nM} \mathrm{N}$-protein in $1 \times$ PBS. Using quantitative image analysis, the LoDs were $1 \mathrm{nM}$ and $0.1 \mathrm{nM}$ N-protein for saliva and $1 \times \mathrm{PBS}$ samples, respectively (Figures $4 \mathbf{B}$ and 4C).

We then investigated the ability of the tests to detect cultured SARS-CoV-2 viruses in saliva and $1 \times$ PBS. In a BSL3 facility, the virus was propagated in cell culture, then lysed and inactivated with $1 \%$ Triton X100 , releasing N-protein. This inactivated virus sample was spiked into saliva and $1 \times \mathrm{PBS}$ and applied to the tests. The colorimetric intensity gradually decreased as viral loads were reduced, and the visual LoDs were around $1.25 \times 10^{5} \mathrm{PFU} / \mathrm{mL}$ (Figure 4D). Quantifying the colorimetric intensity, the LoDs for the cultured virus were determined to be $1.2 \times 10^{4} \mathrm{PFU} / \mathrm{mL}$ and $5.4 \times 10^{3} \mathrm{PFU} / \mathrm{mL}$ in saliva and $1 \times \mathrm{PBS}$, respectively (Figures 4E and 4F). These LoDs correspond to $80 \mathrm{pM}$ and $40 \mathrm{pM}$ N-protein in saliva and $1 \times$ PBS, respectively, according to N-protein concentration in the Triton-inactivated virus prep (Table S5), which was measured using the Simoa SARS-CoV-2 N Protein Antigen assay. ${ }^{31}$ Interestingly, the estimated $\mathrm{N}$-protein concentrations from the cultured virus LoDs are lower than recombinant N-protein LoDs above. The capture binder (SsoNP.E2) was selected against N-protein produced in an insect expression system, allowing for glycosylation and post-translational modifications. It is possible that the capture binder binds to the virus $\mathrm{N}$-protein expressed in mammalian cells with higher affinity than to the recombinant N-protein expressed in E. coli and used for the titrations in Figure 4.

Using N-protein concentration $(116 \mathrm{nM})$ in gamma-irradiated SARS-CoV-2 stock $\left(2.80 \times 10^{5} \mathrm{TCID}_{50} / \mathrm{mL}\right.$, NR-52287, Lot\# 70033322, BEI Resources) (Table S5) as measured by the Simoa SARS-CoV-2 N Protein Antigen assay, we compared our assay performance with that of a published work ${ }^{32}$ and several commercial assays $^{33,34}$ authorized by the Food and Drug Administration (FDA) under an Emergency Use Authorization (EUA). The Global Health Labs assay reported an LoD of $23 \mathrm{TCID}_{50} / \mathrm{mL}$, which is converted to $10 \mathrm{pM} \mathrm{N-}$ protein, and the BD Veritor ${ }^{\mathrm{TM}}$ system and the LumiraDx product claim $140 \mathrm{TCID}_{50} / \mathrm{mL}$ and $32 \mathrm{TCID}_{50} / \mathrm{mL}_{\text {, }}$ which correspond to $58 \mathrm{pM}$ and $14 \mathrm{pM} \mathrm{N}$-protein, respectively. These LoDs are somewhat lower than LoDs demonstrated in our lab ( $80 \mathrm{pM}$ in saliva and $40 \mathrm{pM}$ in $1 \times \mathrm{PBS})$, but they are highly comparable. 
(A)

\begin{tabular}{lc}
\hline \multicolumn{1}{c}{ Virus } & $\begin{array}{c}\text { Concentration } \\
\left(\times 10^{3} \mathrm{PFU} / \mathrm{mL}\right)\end{array}$ \\
\hline SARS-CoV-2 & 250 \\
CoV-229E & 110 \\
CoV-OC43 & 10 \\
H1N1 & 6200 \\
H3N2 & 350 \\
Influenza B & 350
\end{tabular}

(B)

Saliva

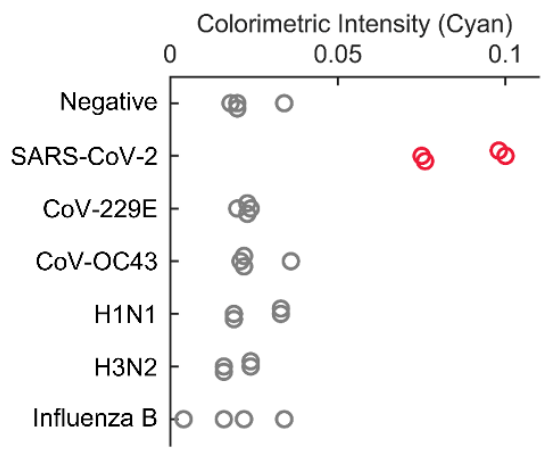

(C)

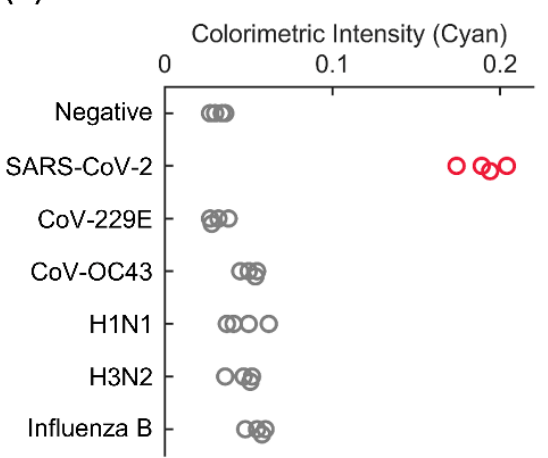

Interference test in saliva and 1xPBS

(D)

\begin{tabular}{|c|c|}
\hline Virus & $\begin{array}{c}\text { Concentration } \\
\left(\times 10^{3} \mathrm{PFU} / \mathrm{mL}\right)\end{array}$ \\
\hline \multirow{2}{*}{ SARS-CoV-2 } & 27 (saliva) \\
\hline & $16(1 \times \mathrm{PBS})$ \\
\hline$+\mathrm{CoV}-229 \mathrm{E}$ & 110 \\
\hline$+\mathrm{CoV}-\mathrm{OC} 43$ & 10 \\
\hline$+\mathrm{H} 1 \mathrm{~N} 1$ & 6200 \\
\hline$+\mathrm{H} 3 \mathrm{~N} 2$ & 350 \\
\hline +Influenza B & 350 \\
\hline
\end{tabular}

(E)

Saliva

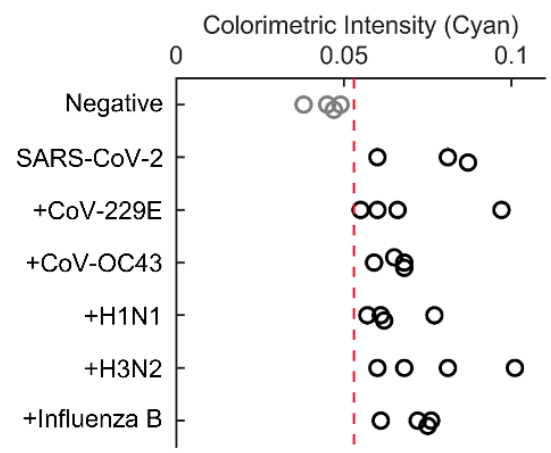

(F)

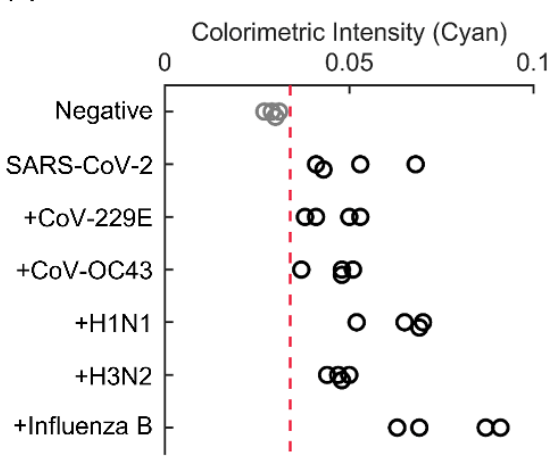

Figure 5. Cross-reactivity and interference tests with cultured SARS-CoV-2 spiked into saliva or $1 \times$ PBS. (A) Viruses and their concentrations used in cross-reactivity tests. $(\mathrm{B}, \mathrm{C})$ Cross-reactivity results in saliva (B) and $1 \times$ PBS (C). No SARS-CoV-2 is included in negative control and other virus samples. (D) Viruses and their concentrations used in interference tests. (E, F) Interference results in saliva (E) and $1 \times P B S(F)$. Except for negative control, smaller concentrations of SARS-CoV-2 than $3 \times \mathrm{LoD}$ are included in saliva $\left(2.7 \times 10^{4} \mathrm{PFU} / \mathrm{mL}\right)$ and $1 \times \mathrm{PBS}\left(1.6 \times 10^{4} \mathrm{PFU} / \mathrm{mL}\right)$. The red dotted lines represent $\mathrm{Neg}+3 \sigma$ as described above. The results demonstrate that our binding pair is highly specific to SARS-CoV-2 N-protein and is not subject to interference from other viruses.

\section{Cross-reactivity and interference tests}

We also examined the specificity of our affinity pair via cross-reactivity and interference tests. To evaluate cross-reactivity of both saliva and mock swab assays, we tested common human coronaviruses (CoV-229E and CoV-OC43), Influenza A (H1N1 and H3N2), and Influenza B with the N-protein assays. The final concentrations $\left(10^{5}-10^{6} \mathrm{PFU} / \mathrm{mL}\right.$ if possible) of the viruses are documented in the table above (Figure 5A). The cultured SARS-CoV-2 was not included in other virus samples except for the positive 
control. Thus, the tests with other viruses produced signals within three standard deviations of the average negative control, demonstrating the high target-specificity of our affinity reagents (Figures 5B and 5C).

For interference tests, we prepared samples of SARS-CoV-2 at concentrations lower than $3 \times$ LoD in saliva $\left(2.7 \times 10^{4} \mathrm{PFU} / \mathrm{mL}\right)$ and $1 \times \mathrm{PBS}\left(1.6 \times 10^{4} \mathrm{PFU} / \mathrm{mL}\right)$, combined with high titers of other viruses $\left(10^{5}-\right.$ $10^{6} \mathrm{PFU} / \mathrm{mL}$ if possible) (Figure 5D) and tested if binding specificity would be maintained. As presented in Figures 5E and 5F, other coronaviruses and influenza viruses did not yield noticeable interfering effects, with all positive SARS-CoV-2 samples giving comparable signals ( $p>0.05)$ above the mean of the negative control plus three standard deviations (red dotted line).
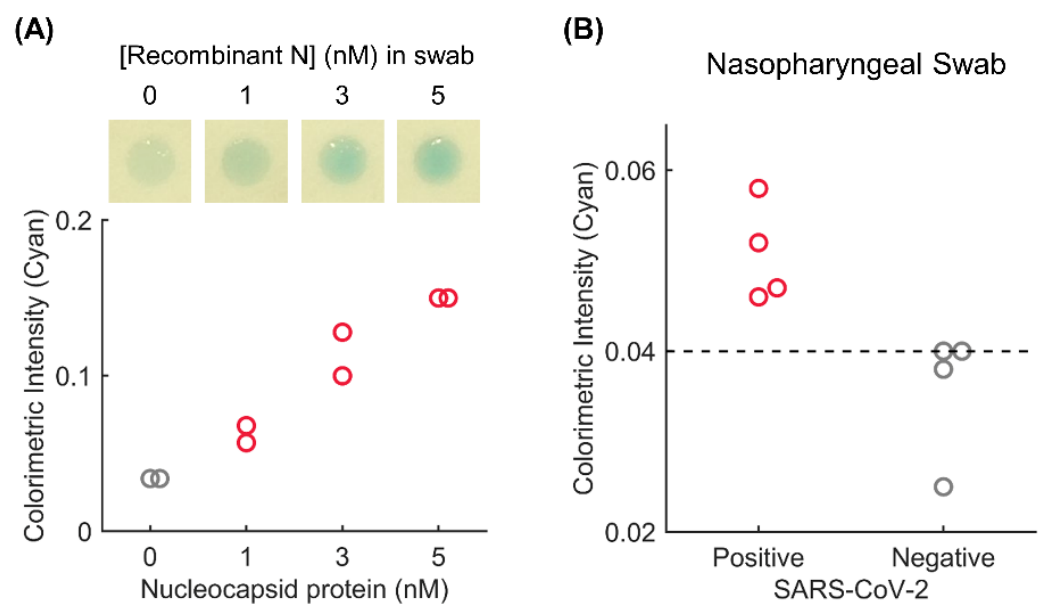

Figure 6. Detection of SARS-CoV-2 N-protein in clinical samples. (A) Detection of recombinant N-protein spiked into negative nasopharyngeal swab matrices. Top: Representative images of the assay results. Bottom: Colorimetric intensity (Cyan) values were calculated using ImageJ. (B) Vertical flow assay results with four RT-PCR positive and four RT-PCR negative nasopharyngeal swab samples. The dotted line represents a cut-off value for the test, which is determined by the largest colorimetric intensity from the negative samples.

\section{Analysis of clinical samples}

Before testing clinical samples, we tested our assays with the recombinant N-protein in nasopharyngeal swab matrix to see if there would be any matrix effects on assay performance. Significant reduction in specific signals was observed when N-protein was spiked into the swab matrix, making even $2.5 \mathrm{nM} \mathrm{N}$ protein hardly detectable (Figure S18). Given that background signals remained unchanged, we hypothesized that the reporting enzyme (HRP) was still functional, but some interfering molecules in the 
swab matrix could hinder specific binding reactions between N-protein and the selected affinity binders. Thus, we added detergent ( $1 \%$ Tergitol TMN) and carrier protein (1\% BSA) to the diluent to reduce the binding interference, boosting signal intensity (Figure 6A). Finally, we validated our assays with clinical nasopharyngeal swab samples. We tested four RT-PCR positive and four RT-PCR negative swab samples (Figure 6B). The concentrations of SARS-CoV-2 N-protein in the RT-PCR-confirmed positive samples were quantified using the Simoa SARS-CoV-2 N Protein Antigen assay. Each sample had at least $1 \mathrm{nM}$ of $\mathrm{N}$-protein, corresponding to the phase of disease with active, replicating viruses. ${ }^{35-37}$ The positive samples induced greater colorimetric intensity than negative samples, demonstrating that rcSso7d-based affinity reagents selected using recombinant $\mathrm{N}$-protein can detect $\mathrm{N}$-protein from viruses in clinical swab samples.

As implied by the small difference in signals between the positive and negative samples, the assay could benefit from further improvement in its sensitivity for diagnostic testing by increasing the sample volume and changing buffer conditions to reduce the matrix effect. However, the current antigen test can be used for screening testing in congregate settings, in which frequent, rapid testing can identify people with a SARS-CoV-2 infection in the early stage of disease progression, preventing transmission. According to recent findings, detection of SARS-CoV-2 RNA does not always infer infectiousness of patients because the RNA persists in bodily fluids much longer than live viruses. ${ }^{38}$ Moreover, a small fraction (2\%) of people with SARS-CoV-2 infections carry most of the virus circulating in communities even in asymptomatic or pre-symptomatic cases, and these super-carriers could silently transmit the virus in communities. ${ }^{39,40}$ Therefore, it is valuable to quickly identify the super-carriers to prevent large outbreaks. We believe the use of the rapid SARS-CoV-2 antigen test for healthy population screening can provide valuable clinical information on infectiousness as reported for other rapid antigen tests. ${ }^{41,42}$ Lastly, we anticipate that the assays manufactured by roll-to-roll processing of cellulose can be an alternative solution to nitrocellulosebased antigen tests in the market, easing supply chain and manufacturing bottlenecks.

\section{CONCLUSION}

The COVID-19 pandemic has clearly demonstrated the critical importance of the rapid development of mass-manufacturable diagnostic or screening tests for enabling a prompt response to emergent infectious diseases. To achieve this goal, we need to quickly identify target biomarkers, develop specific binding pairs against them, and incorporate these affinity reagents into easy-to-scale test formats. In this work, we used the Rapid Affinity Pair Identification via Directed Selection (RAPIDS) method to identify multiple affinity pairs for SARS-CoV-2 nucleocapsid protein (N-protein), a biomarker of COVID-19, from in vitro libraries of $\sim 10^{9}$ variants within 10 weeks. An affinity pair based on the rcSso7d scaffold was integrated into a vertical flow paper-based assay format and was able to detect N-protein from cultured SARS-CoV-2 viruses 
spiked into saliva and $1 \times \mathrm{PBS}$, as well as from characterized clinical swab samples. The compatibility of the capture binder with a roll-to-roll manufacturing process highlights the potential of rcSso7d-based affinity reagents for mass-producible bioactive cellulose-based tests. The rapid selection of affinity pairs for the sensitive, specific detection of a COVID-19 biomarker in contrived and clinical samples in a massproducible test format demonstrates the promise of the RAPIDS technique and engineered binder proteins for timely, flexible development of clinically relevant diagnostic tests.

\section{ASSOCIATED CONTENT}

\section{Supporting Information}

Materials and Methods

Tables S1-S5

Figures S1-S18

\section{AUTHOR INFORMATION}

\section{Corresponding Author}

*E-mail: sikes@mit.edu.

\section{ORCID}

Seunghyeon Kim: 0000-0001-6515-2679

Eric A. Miller: 0000-0002-6217-3922

Yining Hao: 0000-0002-4066-048X

Dousabel M. Y. Tay: 0000-0003-0516-9801

Ki-Joo Sung: 0000-0001-8120-538X

Huan Jia: 0000-0002-8091-8932

Hadley D. Sikes: 0000-0002-7096-138X

\section{Author Contributions}

The paper was written through contributions of all authors. 


\section{Notes}

DYY is an employee of 3M Company. JMJ is an employee of Quanterix Corporation.

\section{ACKNOWLEDGMENTS}

This project was supported by the Deshpande Center for Technological Innovation, anonymous donors to MIT to support COVID-19 research, 3M Company, and the NIH Rapid Acceleration of Diagnostics (RADx) program, funded in whole or in part with Federal funds from the National Institute of Biomedical Imaging and Bioengineering, NIH, under Grant No. U54EB027690. HJ acknowledges support from Singapore's National Research Foundation through the Antimicrobial Resistance Interdisciplinary Research Group.

\section{REFERENCES}

(1) Jayamohan, H.; Lambert, C. J.; Sant, H. J.; Jafek, A.; Patel, D.; Feng, H.; Beeman, M.; Mahmood, T.; Nze, U.; Gale, B. K. SARS-CoV-2 Pandemic : A Review of Molecular Diagnostic Tools Including Sample Collection and Commercial Response with Associated Advantages and Limitations. Anal. Bioanal. Chem. 2020, 1-23.

(2) Singh, A. T.; Lantigua, D.; Meka, A.; Taing, S.; Pandher, M.; Camci-Unal, G. Paper-Based Sensors: Emerging Themes and Applications. Sensors 2018, 18 (9), 2838.

(3) Martinez, A. W.; Phillips, S. T.; Carrilho, E.; Whitesides, G. M. Diagnostics for the Developing World: Microfluidic Paper-Based Analytical Devices. Anal. Chem. 2010, 82 (1), 3-10.

(4) Cate, D. M.; Adkins, J. A.; Mettakoonpitak, J.; Henry, C. S. Recent Developments in Paper-Based Microfluidic Devices. Anal. Chem. 2015, 87 (1), 19-41.

(5) Cheng, C.-M.; Martinez, A. W.; Gong, J.; Mace, C. R.; Phillips, S. T.; Carrilho, E.; Mirica, K. A.; Whitesides, G. M. Paper-Based ELISA. Angew. Chemie - Int. Ed. 2010, 49 (28), 4771-4774.

(6) Wu, Y.; Xue, P.; Kang, Y.; Hui, K. M. Paper-Based Microfluidic Electrochemical Immunodevice Integrated with Nanobioprobes onto Graphene Film for Ultrasensitive Multiplexed Detection of Cancer Biomarkers. Anal. Chem. 2013, 85 (18), 8661-8668.

(7) Schonhorn, J. E.; Fernandes, S. C.; Rajaratnam, A.; Deraney, R. N.; Rolland, J. P.; Mace, C. R. A Device Architecture for Three-Dimensional, Patterned Paper Immunoassays. Lab Chip 2014, 14 (24), 4653-4658.

(8) Deraney, R. N.; Mace, C. R.; Rolland, J. P.; Schonhorn, J. E. Multiplexed, Patterned-Paper Immunoassay for Detection of Malaria and Dengue Fever. Anal. Chem. 2016, 88 (12), 6161-6165.

(9) Ekins, R. More Sensitive Immunoassays. Nature 1980, 284 (5751), 14-15.

(10) Miller, E. A.; Sung, K.-J.; Kongsuphol, P.; Baniya, S.; Aw-Yong, H. Q.; Tay, V.; Tan, Y.; Kabir, 
F. M.; Pang-Yeo, K.; Kaspriskie, I. G.; Sikes, H. D. Beyond Epitope Binning: Directed in Vitro Selection of Complementary Pairs of Binding Proteins. ACS Comb. Sci. 2020, 22, 49-60

(11) Sivasubramanian, A.; Estep, P.; Lynaugh, H.; Yu, Y.; Miles, A.; Eckman, J.; Schutz, K.; Piffath, C.; Boland, N.; Niles, R. H.; Durand, S.; Boland, T.; Vasquez, M.; Xu, Y.; Abdiche, Y. Broad Epitope Coverage of a Human in Vitro Antibody Library. $m A$ Abs 2017, 9 (1), 29-42

(12) Abdiche, Y. N.; Lindquist, K. C.; Stone, D. M.; Rajpal, A.; Pons, J. Label-Free Epitope Binning Assays of Monoclonal Antibodies Enable the Identification of Antigen Heterogeneity. J. Immunol. Methods 2012, 382, 101-116.

(13) Abdiche, Y. N.; Miles, A.; Eckman, J.; Foletti, D.; Van Blarcom, T. J.; Yeung, Y. A.; Pons, J.; Rajpal, A. High-Throughput Epitope Binning Assays on Label-Free Array-Based Biosensors Can Yield Exquisite Epitope Discrimination That Facilitates the Selection of Monoclonal Antibodies with Functional Activity. PLoS One 2014, 9 (3), e92451.

(14) Anderson, G. P.; Liu, J. L.; Zabetakis, D.; Legler, P. M.; Goldman, E. R. Label Free Checkerboard Assay to Determine Overlapping Epitopes of Ebola Virus VP-40 Antibodies Using Surface Plasmon Resonance. J. Immunol. Methods 2017, 442, 42-48.

(15) Cate, D. M.; Hsieh, H. V.; Glukhova, V. A.; Bishop, J. D.; Alonzo, L. F.; Hermansky, H. G.; Barrios-Lopez, B.; Grant, B. D.; Anderson, C. E.; Spencer, E.; Kuhn, S.; Gallagher, R.; Rivera, R.; Bennett, C.; Byrnes, S. A.; Connelly, J. T.; Dewan P. K.; Boyle, D. S.; Weigl, B. H.; Nichols, K. P. Antibody Screening Results for Anti-Nucleocapsid Antibodies Towards the Development of a SARS-CoV-2 Nucleocapsid Protein Analyte Detecting Lateral Flow Assay. ChemRxiv 2020. DOI: 10.26434/chemrxiv.12709538.v2

(16) McMahon, C.; Baier, A. S.; Pascolutti, R.; Wegrecki, M.; Zheng, S.; Ong, J. X.; Erlandson, S. C. Hilger, D.; Rasmussen, S. G. F. Ring, A. M. Yeast Surface Display Platform for Rapid Discovery of Conformationally Selective Nanobodies. Nat. Sctruct. Mol. Biol. 2018, 25 (3), 289-296.

(17) Skerra, A. Lipocalins as a Scaffold. Biochim. Biophys. Acta, Protein Struct. Mol. Enzym. 2000, 369 (4), 1015-1028.

(18) Nygren, P.-A. Alternative Binding Proteins: Affibody Binding Proteins Developed from a Small Three-Helix Bundle Scaffold. FEBS J. 2008, 275 (11), 2668-2676.

(19) Gera, N.; Hussain, M.; Wright, R. C.; Rao, B. M. Highly Stable Binding Proteins Derived from the Hyperthermophilic Sso7d Scaffold. J. Mol. Biol. 2011, 409 (4), 601-616.

(20) Miller, E. A.; Traxlmayr, M. W.; Shen, J.; Sikes, H. D. Activity-Based Assessment of an Engineered Hyperthermophilic Protein as a Capture Agent in Paper-Based Diagnostic Tests. Mol. Syst. Des. Eng. 2016, 1 (4), 377-381.

(21) Zhao, N.; Schmitt, M. A.; Fisk, J. D. Phage Display Selection of Tight Specific Binding Variants from a Hyperthermostable Sso7d Scaffold Protein Library. FEBS J. 2016, 283 (7), 1351-1367.

(22) Bar-on, Y. M.; Flamholz, A.; Phillips, R.; Milo, R. SARS-CoV-2 (COVID-19) by the Numbers. Elife 2020, 1-15.

(23) Carter, L. J.; Garner, L. V.; Smoot, J. W.; Li, Y.; Zhou, Q.; Saveson, C. J.; Sasso, J. M.; Gregg, A. C.; Soares, D. J.; Beskid, T. R.; Jervey, S. R.; Liu, C. Assay Techniques and Test Development for COVID-19 Diagnosis. ACS Cent. Sci. 2020, 6 (5), 591-605.

(24) Weissleder, R.; Lee, H.; Ko, J.; Pittet, M. J. COVID-19 Diagnostics in Context. Sci. Transl. Med. 2020, 12, eabc1931. 
(25) Miller, E. A.; Baniya, S.; Osorio, D.; Maalouf, Y. J. Al; Sikes, H. D. Paper-Based Diagnostics in the Antigen-Depletion Regime: High-Density Immobilization of rcSso7d-Cellulose-Binding Domain Fusion Proteins for Efficient Target Capture. Biosens. Bioelectron. 2018, 102, 456-463.

(26) Sung, K. J.; Miller, E. A.; Sikes, H. D. Engineering Hyperthermostable RcSso7d as Reporter Molecule for in Vitro Diagnostic Tests. Mol. Syst. Des. Eng. 2018, 3 (6), 877-882.

https://www.fda.gov/medical-devices/coronavirus-disease-2019-covid-19-emergency-useauthorizations-medical-devices/vitro-diagnostics-euas (Last accessed: 04/12/2021)

Wyllie, A. L.; Fournier, J.; Casanovas-Massana, A.; Campbell, M.; Tokuyama, M.; Vijayakumar, P.; Warren, J. L.; Geng, B.; Muenker, M. C.; Moore, A. J.; Vogels, C. B. F.; Petrone, M. E.; Ott, I. M.; Lu, P.; Venkataraman, A.; Lu-Culligan, A.; Klein, J.; Earnest, R.; Simonov, M.; Datta, R.; Handoko, R.; Naushad, N.; Sewanan, L. R.; Valdez, J.; White, E. B.; Lapidus, S.; Kalinich, C. C.; Jiang, X.; Kim, D. J.; Kudo, E.; Linehan, M.; Mao, T.; Moriyama, M.; Oh, J. E.; Park, A.; Silva, J.; Song, E.; Takahashi, T.; Taura, M.; Weizman, O.-E.; Wong, P.; Yang, Y.; Bermejo, S.; Odio, C. D.; Omer, S. B.; Dela Cruz, C. S.; Farhadian, S.; Matinello, R. A.; Iwasaki, A.; Grubaugh, N. D.; Ko, A. I. Saliva or Nasopharyngeal Swab Specimens for Detection of SARS-CoV-2. N. Engl. J. Med. 2020, 383 (13), 1283-1286.

(29) Dutta, N. K.; Mazumdar, K.; Gordy, J. T. The Nucleocapsid Protein of SARS-CoV-2: A Target for Vaccine Development. J. Virol. 2020, 94 (13), e00647-20.

(30) Schneider, C. A.; Rasband, W. S.; Eliceiri, K. W. NIH Image to ImageJ: 25 Years of Image Analysis. Nat. Methods 2012, 9 (7), 671-675.

(31) Shan, D.; Johnson, J. M.; Fernandes, S. C.; Suib, H.; Hwang, S.; Wuelfing, D.; Mendes, M.; Holdridge, M.; Burke, E. M.; Beauregard, K.; Zhang, Y.; Cleary, M.; Xu, S.; Yao, X.; Patel, P.; Plavina, T.; Wilson, D.; Chang, L.; Kaiser, K. M.; Natterman, J.; Schmidt, S. V.; Latz, E.; Hrusovsky, K.; Mattoon, D.; Ball, A. J. N-Protein Presents Early in Blood, Dried Blood and Saliva during Asymptomatic and Symptomatic SARS-CoV-2 Infection. Nat. Commun. 2021, 12, 1931.

(32) Grant, B. D.; Anderson, C. E.; Garing, S. H.; Alonzo, L. F.; Williford, J. R.; Baughman, T. A.; Glukhova, V. A.; Boyle, D. S.; Dewan, P. K.; Weigl, B. H.; et al. A SARS-CoV-2 Coronavirus Nucleocapsid Protein Antigen-Detecting Lateral Flow Assay. ChemRxiv 2020. DOI: 10.26434/chemrxiv.12794825.

(33) https://bdveritor.bd.com/content/dam/bdveritor/pdfs/BD-Veritor-IFU.pdf (Last accessed: $04 / 12 / 2021)$

(34) https://www.lumiradx.com/assets/pdfs/covid-19-antigen-test/sars-cov-2-antigen-testspecifications/sars-cov-2-ag-test-spec-sheet-ous.pdf?v=5 (Last accessed: 04/12/2021)

(35) Gniazdowski, V.; Morris, C. P.; Wohl, S.; Mehoke, T.; Srividya, R.; Thielen, P.; Powell, H.; Smith, B.; Armstrong, D. T.; Herrera, M.; Reifsnyder, C.; Sevdali, M.; Carroll, K. C.; Pekosz, A.; Mostafa, H. H. Repeat COVID-19 Molecular Testing: Correlation with Recovery of Infectious Virus, Molecular Assay Cycle Thresholds, and Analytical Sensitivity. MedRxiv 2020. DOI: 10.1101/2020.08.05.20168963.

(36) La Scola, B.; Le Bideau, M.; Andreani, J.; Hoang, V. T.; Grimaldier, C.; Colson, P.; Gautret, P.; Raoult, D. Viral RNA Load as Determined by Cell Culture as a Management Tool for Discharge of SARS-CoV-2 Patients from Infectious Disease Wards. Eur. J. Clin. Microbiol. Infect. Dis. 2020, 39 (6), 1059-1061.

Jaafar, R.; Aherfi, S.; Wurtz, N.; Clio, G.; Hoang, V. T.; Colson, P.; Raoult, D.; La Scola, B. 
Corrleation Between 3790 Quantitative Polymerase Chain Reaction-Positives Samples and Positive Cell Cultures, Including 1941 Severe Acute Respiratory Syndrome Coronavirus 2 Isolates. Clin. Infect. Dis. 2020, ciaa1491.

(38) Cevik, M.; Tate, M.; Lloyd, O.; Maraolo, A. E.; Schafers, J.; Ho, A. SARS-CoV-2, SARS-CoV, and MERS-CoV Viral Load Dynamics, Duration of Viral Shedding, and Infectiousness: A Systematic Review and Meta-Analysis. The Lancet Microbe 2021, 2 (1), E13-E22.

(39) Yang, Q.; Saldi, T. K.; Lasda, E.; Decker, C. J.; Paige, C. L.; Muhlrad, D.; Gonzales, P. K.; Fink, M. R.; Tat, K. L.; Hager, C. R.; Davis, J. C.; Ozeroff, C. D.; Meyerson, N. R.; Clark, S. K.; Fattor, W. T.; Gilchrist, A. R.; Barbachano-Guerrero, A.; Worden-Sapper, E. R.; Wu, S. S.; Brisson, G. R.; McQueen, M. B.; Dowell, R. D.; Leinwand, L.; Parker, R.; Sawyer, S. L. Just 2\% of SARSCoV-2-Positive Individuals Carry 90\% of the Virus Circulating in Communities. MedRxiv 2021. DOI: $10.1101 / 2021.03 .01 .21252250$.

(40) Bjorkman, K. K.; Saldi, T. K.; Lasda, E.; Bauer, L. C.; Kovarik, J.; Gonzales, P. K.; Fink, M. R.; Tat, K. L.; Hager, C. R.; Davis, J. C.; Ozeroff, C. D.; Brisson, G. R.; Larremore, D. B.; Leinwand, L. A.; McQueen, M. B.; Parker, R. Higher Viral Load Drives Infrequent SARS-CoV-2 Transmission between Asymptomatic Residence Hall Roommates. MedRxiv 2021. DOI: 10.1101/2021.03.09.21253147.

(41) Albert, E.; Torres, I.; Bueno, F.; Huntley, D.; Molla, E.; Fernández-Fuentes, M. A.; Martínez, M.; Poujois, S.; Forque, L.; Valdivia, A.; de la Asunción, C. S.; Ferrer, J.; Colomina, J.; Navarro, D. Field Evaluation of a Rapid Antigen Test (Panbio COVID-19 Ag Rapid Test Device) for COVID19 Diagnosis in Primary Healthcare Centres. Clin. Microbiol. Infect. 2021, 27, 472.e7-472.e10.

(42) Pekosz, A.; Cooper, C. K.; Parvu, V.; Li, M.; Andrews, J. C.; Manabe, Y. C.; Kodsi, S.; Leitch, J.; Gary, D. S.; Roger-Dalbert, C. Antigen-Based Testing But Not Real-Time PCR Correlates with SARS-CoV-2 Virus Culture. Clin. Infect. Dis. 2021, ciaa1706 


\section{TABLE OF CONTENT FIGURE}

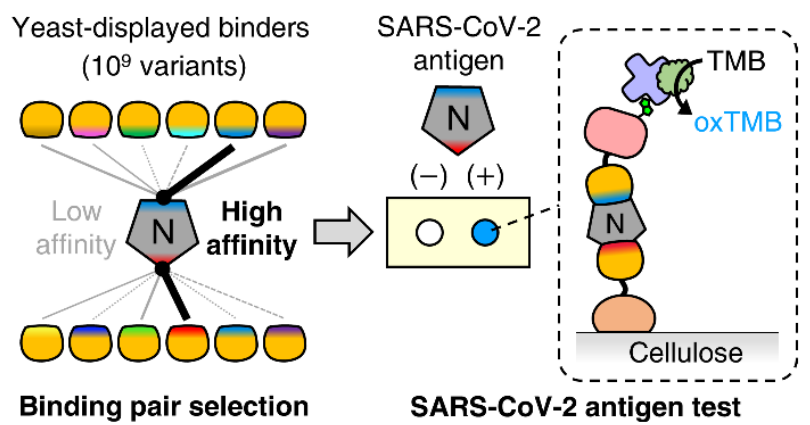

\section{SYNOPSIS}

Rapid selection of affinity pairs for antigens indicating COVID-19 demonstrates the promise of engineered binder proteins for timely development of diagnostic tests in response to emerging infectious diseases. 


\title{
Supporting Information
}

\section{Developing a SARS-CoV-2 antigen test using engineered affinity proteins}

\author{
Seunghyeon Kim $^{a \dagger}$, Emma Yee ${ }^{a \dagger}$, Eric A. Miller ${ }^{a}$, Yining Hao ${ }^{a}$, Dousabel M. Y. Tay ${ }^{a}$, Ki-Joo Sung ${ }^{a}$, Huan \\ Jia $^{b}$, Joseph M. Johnson ${ }^{c}$, Mohsan Saeed $^{d, e}$, Charles R. Mace ${ }^{f}$,Deniz Yüksel Yurt ${ }^{g}$, and Hadley D. Sikes ${ }^{a, b^{*}}$ \\ ${ }^{a}$ Department of Chemical Engineering, Massachusetts Institute of Technology, Cambridge, MA 02139, USA \\ ${ }^{b}$ Antimicrobial Resistance Integrated Research Group, Singapore-MIT Alliance for Research and Technology,
}

\author{
1 CREATE Way, Singapore 138602, Singapore \\ ${ }^{c}$ Quanterix Corporation, Billerica, MA 01821, USA \\ ${ }^{d}$ Department of Biochemistry, Boston University School of Medicine, Boston, MA 02118, USA \\ ${ }^{e}$ National Emerging Infectious Diseases Laboratories (NEIDL), Boston, MA 02188, USA \\ fDepartment of Chemistry, Tufts University, Medford, MA 02155, USA \\ g3M Company, St. Paul, MN 55133, USA
}

†These authors equally contributed to this work.

${ }^{*}$ Corresponding Author:

Prof. Hadley D. Sikes

E-mail: sikes@mit.edu 


\section{Table of Contents}

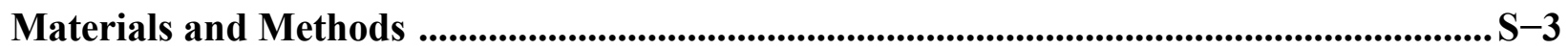

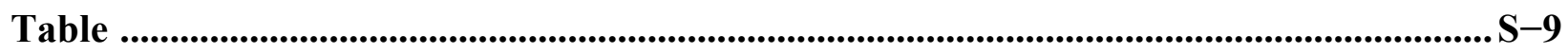

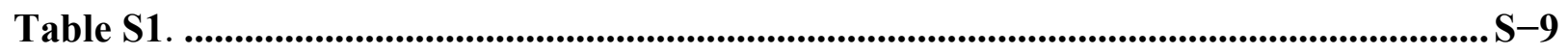

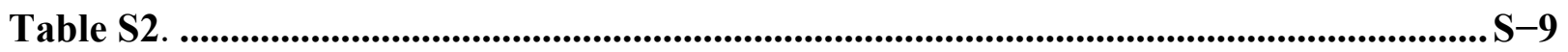

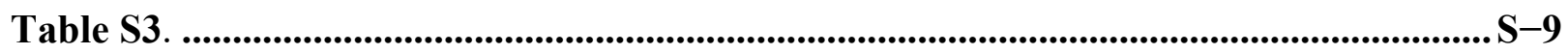

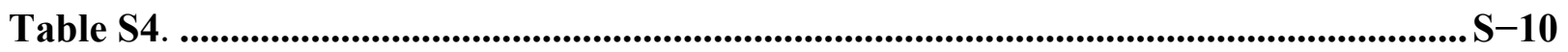

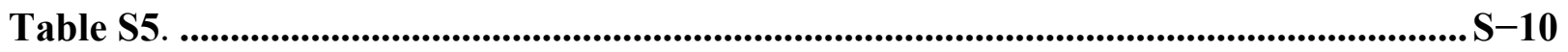

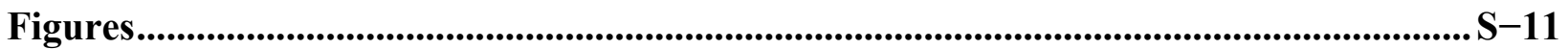

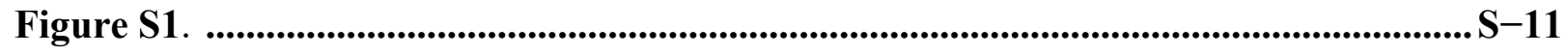

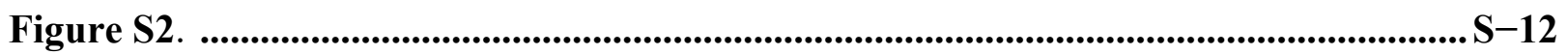

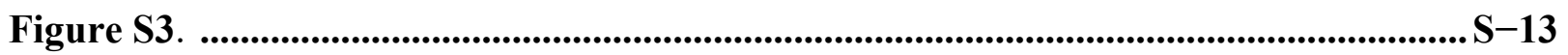

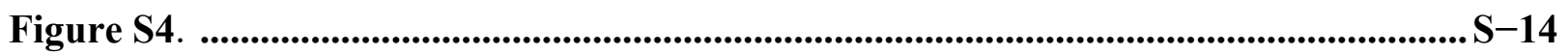

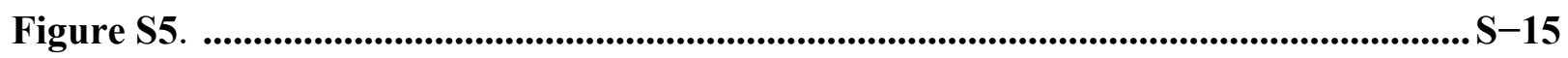

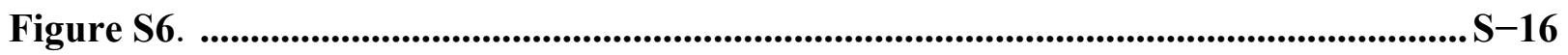

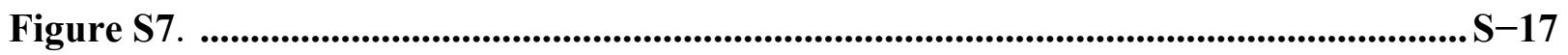

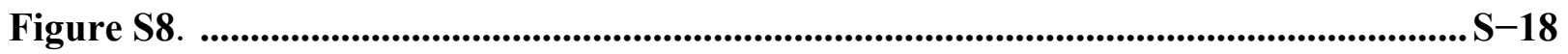

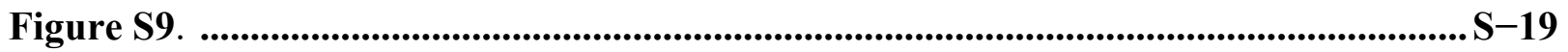

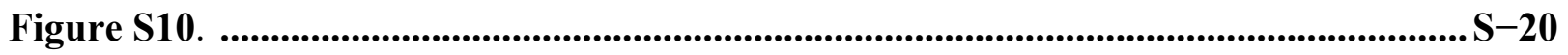

Figure S11. ............................................................................................................................... S-21

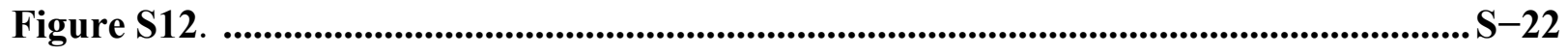

Figure S13. ................................................................................................................................ S-23

Figure S14. ............................................................................................................................... S-25

Figure S15. ............................................................................................................................. S-26

Figure S16. .............................................................................................................................. S-27

Figure S17. ............................................................................................................................ S-28

Figure S18. ................................................................................................................................ S-29

Reference …............................................................................................................................... S-29 


\section{Materials and Methods}

\section{Materials}

Chicken anti-c-Myc (ACMYC) and chicken anti-HA (AHA) were purchased from Exalpha Biologicals (Shirley, MA, USA). Mouse anti-HA.11 (clone 16B12) was purchased from Biolegend (Sandiego, CA, USA). D-biotin (B4639), 10×phosphate buffered saline (PBS), and TERGITOL TMN-100X solution (STS0004) were purchased from MilliporeSigma (St. Louis, MO, USA). TMB substrate solution (34028), 10\% BSA in $1 \times$ PBS (37525), Pierce BCA Protein Assay Kit (23225), Pierce Monomeric Avidin Agarose Kit (432040), B-PER Bacterial Protein Extraction Reagent (90084), mouse anti-6x-His (clone MA1-21315, HIS.H8), goat anti-mouse AlexaFluor (AF) 647 (A-21235), goat anti-chicken AF488 (A-11039), streptavidin AF647 (S-21374), Dynabeads Biotin Binder (11047), HisPur NiNTA Magnetic Beads (88831), Pierce High Sensitivity Streptavidin-HRP (21130), Pierce High Sensitivity Neutravidin-HRP (31030), and Blocker Casein in PBS (37582) were purchased from Thermo Fisher Scientific (Waltham, MA, USA). Whatman Grade 1 Chr Cellulose Chromatography paper (21427-003), glycerol (97062-452), Kanamycin sulfate (97061-600), Terrific Broth Powder (97063-418), and isopropyl- $\beta$-D-thiogalactoside (IPTG) 99\% dioxane-free (AAB21149-06) were obtained from VWR (Radnor, PA, USA). Blot paper (1703965), 4-15\% Mini-PROTEAN TGX Stain-Free Protein Gels (4568084), Precision Plus Protein Dual Color Standards (1610374), and Nuvia IMAC Resin (7800800) were purchased from Bio-Rad Laboratories, Inc. (Hercules, CA, USA). Restriction enzyme NdeI (R0111S), XhoI (R0146S), BamHI (R3136S), and EcoRI (R3101S) were purchased from New England BioLabs (Ipswich, MA, USA). SARS-CoV Nucleocapsid Protein (His Tag) (40143-V08B) was purchased from Sino Biological (Wayne, PA, USA). A single lot of Great Lakes Filters filter paper grade 024 (Whatman Grade $1 \mathrm{Chr}$ equivalent) was provided by 3M Company (St. Paul, MN, USA) to eliminate lot-to-lot variability for these studies. PCR verified SARS-CoV-2 positive and negative patient samples were procured by Lee Biosolutions and provided as de-identified samples.

\section{Production of gene constructs}

Recombinant SARS-CoV-2 nucleocapsid protein (N-Protein) was cloned into pET28b(+) between NdeI and $\mathrm{XhoI}$ restriction sites for bacterial expression. The N-protein sequence was acquired from NCBI and synthesized by Genewiz. ${ }^{1}$ rcSso7d variants discovered using RAPIDS were cloned from the pCTCON2

yeast surface display plasmid into pET28b(+) bacterial expression plasmids as described previously. ${ }^{2,3}$ Two different plasmid constructs were used: 1) N-terminal AviTag biotin acceptor (BA) sequence with maltosebinding protein (MBP) (BA-MBP-reporter rcSso7d), 2) C-terminal cellulose-binding domain (CBD) 
(Capture rcSso7d-CBD). Each of the plasmid constructs contains an N-terminal hexahistidine tag for purification purposes. Successfully cloned plasmids were verified via sequencing and stored in DH5 $E$. coli cell stocks and also transformed into BL21(DE3) E. coli for protein expression.

\section{Protein expression, purification, and characterization}

For protein expression, BL21 (DE3) E. coli strains were cultured at $37^{\circ} \mathrm{C}$ in Terrific Broth supplemented with kanamycin at a concentration of $50 \mu \mathrm{g} / \mathrm{mL}$ and induced at an $\mathrm{OD}_{600}$ of 0.4 using a final concentration of $0.5 \mathrm{mM}$ isopropyl $\beta$-D-1-thiogalactopyranoside (IPTG). For the biotinylated MBP-reporter, the growth medium was supplemented with $0.2 \mathrm{mM}$ of D-biotin at the time of induction. Induced cultures were incubated at $20^{\circ} \mathrm{C}$ for $16-20$ hours and then harvested using centrifugation.

For N-protein purification, the cells were resuspended in Equilibration buffer A (50 mM Tris, $300 \mathrm{mM}$ $\mathrm{NaCl}$, and $10 \mathrm{mM}$ imidazole) and lysed via sonication. The lysate was clarified via centrifugation, and the soluble fraction was sterile filtered. The $\mathrm{N}$ protein was separated from E. coli proteins using Ni-NTA immobilized metal affinity chromatography (IMAC) with ÄKTA Start (Cytiva). The protein bound to the column was washed with $100 \%$ Equilibration buffer A for $10 \times$ column volume $(1 \mathrm{~mL} / \mathrm{min}$ for 10 minutes for $1 \mathrm{~mL}$ column). The column was then washed with 92\% Equilibration buffer A and 8\% Equilibration buffer B (50 mM Tris, $300 \mathrm{mM} \mathrm{NaCl}$, and $500 \mathrm{mM}$ imidazole) for $10 \times$ column volume $(1 \mathrm{~mL} / \mathrm{min}$ for 10 minutes for $1 \mathrm{~mL}$ column). The protein was then eluted using a gradient. The concentration of Equilibration buffer $\mathrm{B}$ was increased from $8 \%$ to $100 \%$ over 10 minutes with a $1 \mathrm{~mL} / \mathrm{min}$ flow rate.

The insoluble fraction of $\mathrm{N}$ protein preparations was re-solubilized with urea buffer (50 mM Tris, 300 $\mathrm{mM} \mathrm{NaCl}, 10 \mathrm{mM}$ imidazole, and $8 \mathrm{M}$ Urea) overnight at $4{ }^{\circ} \mathrm{C}$. The solubilized, denatured protein was sterile filtered and loaded onto an IMAC column in urea buffer and refolded on the column by performing a refolding gradient. The gradient of Equilibration buffer A increased from 0 to $100 \%$ over 10 minutes at 1 $\mathrm{mL} / \mathrm{min}$ flow rate. The column was washed for $10 \times$ column volume by $100 \%$ Equilibration buffer $\mathrm{A}$, followed by $10 \times$ column volume of $92 \%$ Equilibration buffer $\mathrm{A}$ and $8 \%$ Equilibration buffer $\mathrm{B}$. The product was eluted using a gradient where the concentration of buffer B was increased to $100 \%$ over 10 minutes with a $1 \mathrm{~mL} / \mathrm{min}$ flow rate.

For biotinylated MBP-reporter binder purification, the cell pellets were harvested and frozen at $-20{ }^{\circ} \mathrm{C}$ overnight or snap frozen using liquid nitrogen. After at least one freeze-thaw cycle, the cells were resuspended in B-PER ( $5 \mathrm{~mL}$ per g cell pellet) to lyse, because lysis via sonication led to variability in binding activity. The cells were incubated at room temperature in B-PER for up to 60 minutes, and the supernatant was collected and purified using a Ni-NTA IMAC column and an ÄKTA Start. After loading the protein,

$$
\mathrm{S}-4
$$


the column was washed with $10 \times$ column volume $(1 \mathrm{~mL} / \mathrm{min}$ for 10 minutes for $1 \mathrm{~mL}$ column $)$ of Equilibration buffer A, and the protein was eluted with a gradient. The concentration of Equilibration buffer $\mathrm{B}$ was increased from $0 \%$ to $100 \%$ over 10 minutes with a $1 \mathrm{~mL} / \mathrm{min}$ flow rate.

For capture binder-CBD purification, the cells were lysed via sonication in Equilibration buffer A, and the soluble fraction was purified using an IMAC column and an ÄKTA Start. The protein on the column was washed with $100 \%$ Equilibration buffer A for $10 \times$ column volume $(1 \mathrm{~mL} / \mathrm{min}$ for 10 minutes for $1 \mathrm{~mL}$ column). The protein was eluted using a gradient. The concentration of Equilibration buffer B was increased from $0 \%$ to $100 \%$ over 10 minutes with a $1 \mathrm{~mL} / \mathrm{min}$ flow rate.

For each of the above preparations, fractions containing the desired recombinant protein were immediately concentrated using an Amicon Ultra Centrifugal Filter (MWCO $=10 \mathrm{kDa}$ ) and buffer exchanged into 1X phosphate buffered saline, $\mathrm{pH} 7.4$ (PBS).

Purified proteins were quantified using a bicinchoninic acid (BCA) assay with BSA standards, and protein purity was assessed by separating $1.5 \mu \mathrm{g}$ of the preparation using $4-15 \%$ Mini-PROTEAN TGX Stain-Free Protein Gels with the Bio-Rad protein ladder (1610374). The rcSso7d clones and rcSso7d fusion proteins were stored at $4{ }^{\circ} \mathrm{C}$, and $\mathrm{N}$-protein was aliquoted and stored at $-20{ }^{\circ} \mathrm{C}$ in $50 \%(\mathrm{v} / \mathrm{v})$ glycerol. Capture binder stocks were approximately $1 \mathrm{mM}$. Reporter binder stocks were hundreds of $\mu \mathrm{M}$, and SARSCoV-2 stocks were tens of $\mu \mathrm{M}$.

\section{Magnetic bead sorting}

Magnetic bead sorting (MBS) was conducted to narrow down reporter binder candidates as previously described. ${ }^{3,4}$ HisPur Ni-NTA beads were incubated overnight at $4{ }^{\circ} \mathrm{C}$ with five nanomoles of recombinant SARS-CoV-2 N-protein for immobilization of the N-protein using its hexahistidine tag. The beads were washed and incubated with 20 -fold library representation. Following a two-hour incubation with the yeast library, beads were washed four times, pooled, and inoculated into SDCAA media, taking care to wash all tubes multiple times to ensure full bead/yeast retention. Following the first MBS (MBS1), the resulting sublibrary was induced in $2 \mathrm{~g} / \mathrm{L}$ dextrose-supplemented SGCAA over the course of 16 hours, and $1 \times$ the library size $\left(1.4 \times 10^{9}\right.$ cells $)$ was then contacted with $2.62 \mu \mathrm{L}$ of bare HisPur Ni-NTA beads for 1.5 hours. This negative selection was repeated a total of three times, and the depleted library was then contacted with 2.6 $\mu \mathrm{L}$ of HisPur Ni-NTA beads which had previously been incubated with 0.25 nanomoles of the N-protein for two hours. Following the second positive sorting (MBS2), retained cells were inoculated into SDCAA 
and allowed to grow over the course of 16 hours, followed by 16 hours' induction in dextrose-supplemented SGCAA.

\section{Fluorescence-activated cell sorting}

Fluorescence-activated cell sorting (FACS) was conducted to select reporter binder candidates as previously described. ${ }^{4}$ The post-MBS2 sub-library was sorted via FACS (6 million cells), with an initial depletion step to remove truncated binders, as well as binders which interacted with the mouse anti-His or goat anti-Mouse AF647 labeling reagents. The depleted population was immediately relabeled with the Nprotein at $100 \mathrm{nM}$, and the top $10 \%$ of binders was captured in the population with 50,000 cells. This postFACS1 population was relabeled with $20 \mathrm{nM}$ N-protein, and 6,500 cells were captured. Clonal analysis with the post-FACS2 population yielded six reporter rcSso7d clones, and the lead candidate was chosen as reporter binder (SsoNP.E1).

Prior to FACS to discover affinity pairs, biotinylated MBP-SsoNP.E1 purified from E. coli was prepared and used to identify which library iteration should be used. The post-FACS2 library was labeled as previously described, ${ }^{4}$ and used to identify one capture rcSso $7 \mathrm{~d}$ targeting a distinct epitope of the N-protein. Given the high degree of homology between SARS-CoV and SARS-CoV-2 N-proteins, ${ }_{5}^{5}$ SARS-CoV-1 Nprotein produced in baculovirus (BacN), offering post-translational modifications, was also used as a target biomarker with biotinylated MBP-SsoNP.E1 as a reporter reagent to identify capture binder clones targeting different epitopes. Four rounds of secondary FACS sorting with BacN and biotinylated MBP-SsoNP.E1 were conducted starting from the post-MBS2 sub-library, which featured greater clonal diversity than the post-FACS2 sub-library and yielded novel, high-affinity binding partners.

FACS was conducted on a BD FACS Aria running the FACS Diva software package. The forward scatter and side scatter parameters were used in series to identify and select singlet cell populations. Alexa Fluor 647 was excited using a laser at $640 \mathrm{~nm}$, and fluorescence was detected using a filter measuring emission at $670 \mathrm{~nm}$, with a $30 \mathrm{~nm}$ bandwidth. Alexa Fluor 488 was excited using a laser at $488 \mathrm{~nm}$, and fluorescence was detected using a filter measuring emission at $515 \mathrm{~nm}$, with a $20 \mathrm{~nm}$ bandwidth. Cytometry data was analyzed using the FlowJo software package.

\section{Sample processing}

When used with patient samples, $1 \mathrm{v} / \mathrm{v} \%$ Triton X-100 must be used to lyse any SARS-CoV-2 viruses in

the patient samples (saliva or swab). Triton X-100 is a non-ionic detergent that has been shown to effectively inactivate SARS-CoV-2 in nasal swab matrix, serum, and tissue culture fluid. ${ }^{6}$ Viral S-6 
inactivation/lysis is necessary to release the N-protein from inside the enveloped virus. Therefore, all simulated samples (human saliva or $1 \times$ PBS spiked with recombinant N-protein or cultured SARS-CoV-2 viruses) were similarly treated to replicate relevant clinical processing conditions.

To obtain tissue culture-generated SARS-CoV-2, Vero E6 cells were infected with the virus at a multiplicity of infection of 0.01 for $48 \mathrm{~h}$ in a BSL3 lab, and the culture medium was collected and passed through $0.45 \mu \mathrm{m}$ filters. Triton X-100 was added to the culture medium to obtain the final concentration of $1 \%$, and the mixture was incubated at $4{ }^{\circ} \mathrm{C}$ for $3 \mathrm{~h}$ to achieve complete virus lysis/inactivation. The outer surface of the tubes was then wiped with freshly prepared $10 \%$ bleach, and the tubes were transferred to BSL2 where they were stored at $-80{ }^{\circ} \mathrm{C}$.

Saliva was collected from volunteers who tested negative for COVID-19 on the same day as collection. Volunteers brushed their teeth and consumed nothing but water before collection via passive drooling. Saliva was filtered through a $0.8 \mu \mathrm{m}$ syringe filter to remove mucins, and $1 \mathrm{v} / \mathrm{v} \%$ Triton-X-100 was added to the filtrate. This solution was used as negative control or spiked with recombinant N-protein or lysed viral culture in experiments.

Clinical swab samples which were PCR-verified to be positive for SARS-CoV-2 were inactivated with $1 \mathrm{v} / \mathrm{v} \%$ Triton $\mathrm{X}-100$ for two minutes prior to mixing with reagents. These experiments were conducted following approved biosafety procedures resulting from a formal risk assessment, and according to the recommendations of the $\mathrm{CDC}$ for routine diagnostic testing. Mock swab samples were prepared by adding $1 \mathrm{v} / \mathrm{v} \%$ Triton $\mathrm{X}-100$ to $1 \times \mathrm{PBS}$.

\section{Assay protocol on single-layer paper-based assays}

Test strips were made by printing a pattern containing a circular wax-free region on Whatman no. 1 chromatography paper and melting the paper printed with solid ink (Xerox ColorQube) in an oven $\left(150{ }^{\circ} \mathrm{C}\right)$ for $30 \mathrm{~s}$. The wax-free test zones were rinsed with deionized water, and the washed zones were placed in a humid chamber in a way that only the edge of the test strips were in contact with other surfaces. Each test zone was coated with $0.5 \mu \mathrm{L}$ of $5 \mu \mathrm{M}$ capture binder-CBD and blocked with $0.5 \mu \mathrm{L} 1 \times$ PBSA. Sample solutions including $0 \mathrm{nM}$ or $100 \mathrm{nM}$ N-protein, $100 \mathrm{nM}$ biotinylated MBP-SsoNP.E1, and $50 \mathrm{pM}$ streptavidin-HRP in $1 \times$ PBSA were prepared five minutes before being added to the test zones $(10 \mu \mathrm{L}$ per well). The mixture is incubated on paper for five minutes before rinsing twice with $20 \mu \mathrm{L}$ of $1 \times \mathrm{PBS}$. Finally, TMB substrate solution is added to washed test zones to develop blue color for five minutes, followed by imaging. 


\section{Production of vertical flow paper-based assays}

Great Lakes Filters filter paper grade 024 (Whatman Grade $1 \mathrm{Chr}$ equivalent) was used for this assay. Hydrophobic barriers were created to outline hydrophilic wells and flow pathways using a UV-curable resin which was applied to rolls of cellulose paper via a template. Capture binder (SsoNP.E2-CBD) was either applied manually in $0.5 \mu \mathrm{L}$ volumes of $30 \mu \mathrm{M}$ binder in $1 \times \mathrm{PBS}$ or applied via a commercial deposition device at 3M Company (St. Paul, MN, USA). Blocking solution of $0.5 \mathrm{w} / \mathrm{v} \%$ casein, $5 \mathrm{w} / \mathrm{v} \%$ sucrose, 0.1 $\mathrm{v} / \mathrm{v} \%$ Tween-20 in $0.1 \mathrm{M}$ phosphate buffer ( $\mathrm{pH}$ 6.3) with $150 \mathrm{mM} \mathrm{NaCl}$ was applied either manually or deposited via machine in $1 \mu \mathrm{L}$ volumes and allowed to dry. Multilayer tests were assembled by cutting out individual test strips from a UV-cured roll and folding them accordion-style. A square of Bio-Rad's absorbent blot paper (\#1703965) was applied on the bottom layer and the device was tightly clipped together with binder clips. The assembled devices were stored away from direct sunlight at room temperature in a dry place until use.

\section{Assay protocol on vertical flow paper-based assays}

For saliva-based tests, equal volume amounts of saliva (with or without N-protein) was mixed with a solution of $100 \mathrm{nM}$ biotinylated MBP-SsoNP.E1 and $50 \mathrm{ng} / \mathrm{mL}$ streptavidin-HRP in diluent $(0.2 \mathrm{M}$ phosphate buffer, $\mathrm{pH}$, with $150 \mathrm{mM} \mathrm{NaCl}, 5 \mathrm{w} / \mathrm{v} \% \mathrm{BSA}$, and $0.5 \mathrm{w} / \mathrm{v} \%$ CHAPS). Immediately after mixing the sample and reagents, $20 \mu \mathrm{L}$ of the diluted sample was applied to each sample port and allowed to flow through completely. Once no liquid was visible at the top of the assay, $50 \mu \mathrm{L}$ of wash buffer (same as diluent) was applied and allowed to flow through completely.

For simulated swab tests, mock swab samples treated with $1 \%$ Triton $\mathrm{X}-100$ were mixed at a ratio of 14:1 with concentrated reagents of $750 \mathrm{nM}$ biotinylated MBP-SsoNP.E1 and $2 \mu \mathrm{g} / \mathrm{mL}$ neutravidin-HRP in $0.15 \mathrm{M}$ phosphate buffer ( $\mathrm{pH}$ 6). Immediately after mixing the sample and reagents, $15 \mu \mathrm{L}$ of the mixture was applied to each sample port and allowed to flow through. Once no liquid was visible at the top of the assay, $50 \mu \mathrm{L}$ of wash buffer $(0.2 \mathrm{M}$ phosphate buffer, $\mathrm{pH}$, with $150 \mathrm{mM} \mathrm{NaCl}, 5 \mathrm{w} / \mathrm{v} \% \mathrm{BSA}$, and $1 \mathrm{w} / \mathrm{v} \%$ CHAPS) was applied and also allowed to flow through completely. Neutravidin-HRP was used instead of streptavidin due to lower non-specific binding in the $1 \times$ PBS system. For nasopharyngeal swab-based tests, the concentrated reagents were prepared in $0.15 \mathrm{M}$ phosphate buffer $(\mathrm{pH} 6)$ with $1 \mathrm{v} / \mathrm{v} \%$ Tergitol TMN and $1 \mathrm{w} / \mathrm{v} \% \mathrm{BSA}$. 
For both tests, after wash flowed through, the device was unclipped and the wicking pad was removed. The test was turned upside down, and $3 \mu \mathrm{L}$ of TMB solution was applied to each test zone, followed by imaging after two minutes.

\section{Imaging}

Tests were imaged in a windowless room with constant overhead lighting using a Fujifilm X-E2S digital camera with constant focus, aperture, and shutter speed setting. Tests were placed in a shallow, ceiling-less Styrofoam box to reduce glare. Images were analyzed in ImageJ by quantifying mean cyan channel. Given that the absorbance peak of oxidized TMB is $\sim 650 \mathrm{~nm}$ (red light) ${ }^{7}$, colorimetric intensity and reaction extent is directly linked to red light channels. Cyan is defined as an inverse red channel, and therefore correlated well with visible colorimetric intensity and reaction extent. 


\section{Tables}

Table S1. Amino acid sequences of selected reporter clones. The amino acid sequences in the binding face of the rcSso $7 \mathrm{~d}$ clone are bolded and underlined.

\begin{tabular}{|c|c|c|}
\hline $\begin{array}{l}\text { Reporter } \\
\text { Clones }\end{array}$ & $\begin{array}{l}\text { Binding face } \\
\text { shorthand tag }\end{array}$ & Protein sequence $(\mathrm{N} \rightarrow \mathrm{C})$ \\
\hline 1 & IRGWSWYAY & 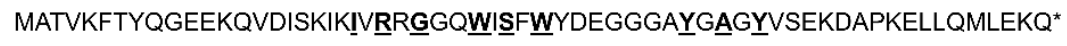 \\
\hline 2 & IRRHSWWAY & 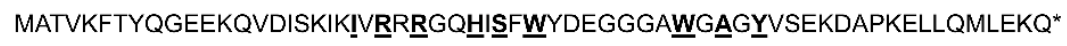 \\
\hline 3 & IRRRSWWAY & 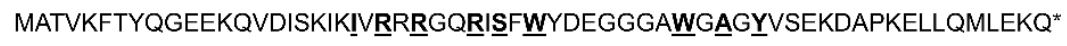 \\
\hline 4 & IRSHSWWGY & 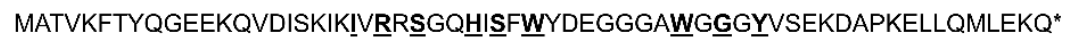 \\
\hline 5 & IKGYSWWAY & 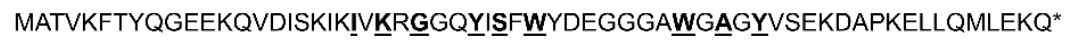 \\
\hline 6 & IRKHSWYAY & 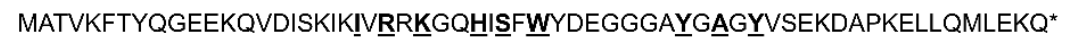 \\
\hline
\end{tabular}

Table S2. Amino acid sequences of selected capture clones. The amino acid sequences in the binding face of the rcSso7d clone are bolded and underlined.

\begin{tabular}{|c|c|c|}
\hline $\begin{array}{l}\text { Capture } \\
\text { Clones }\end{array}$ & $\begin{array}{l}\text { Binding face } \\
\text { shorthand tag }\end{array}$ & Protein sequence $(\mathrm{N} \rightarrow \mathrm{C})$ \\
\hline SsoNP.E2-1 & YAWKHSAWYD & MATVKFTYQGEEKQVDISKIK $\underline{Y A} \bigvee \underline{w} R \underline{K} G Q \underline{H} \mid \underline{S} F \underline{A} Y D E G G G A \underline{W} G \underline{Y} G \underline{D} V S E K D A P K E L L Q M L E K Q^{*}$ \\
\hline SsoNP.E2-2 & NGWIDDIIA & 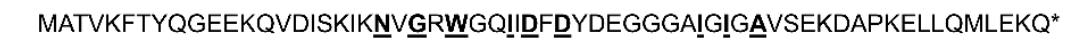 \\
\hline SsoNP.E2-3 & IWKGDDIWW & 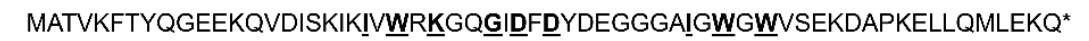 \\
\hline
\end{tabular}

Table S3. Amino acid sequences of binder protein fusion constructs. The amino acid sequences in the binding face of the rcSso7d clone are bolded and underlined.

\begin{tabular}{|c|c|}
\hline Construct & Protein sequence $(\mathrm{N} \rightarrow \mathrm{C})$ \\
\hline BA-MBP-SsoNP.E1 & 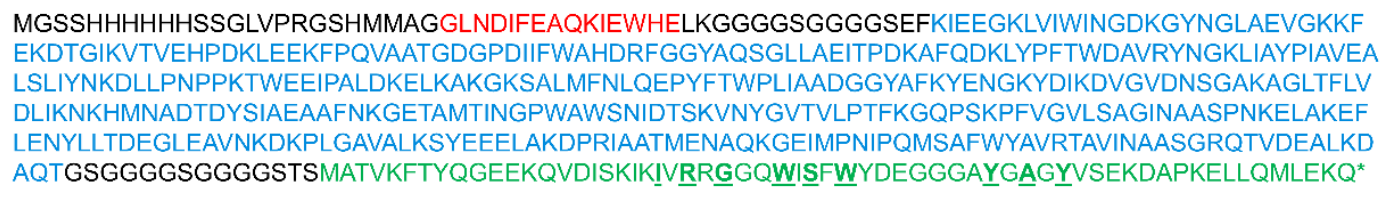 \\
\hline SsoNP.E2-CBD & $\begin{array}{l}\text { MGSSHHHHHHSSGLVPRGSHMATVKFTYQGEEKQVDISKIKNVGRWGQIIDFDYDEGGGAIGIGAVSEKDAPKELLQMLEKQ } \\
\text { GSGGGGSGGGGSGGGGSPSGNLKVEFYNNPSTTNSINPQFKVTNTGSSAIDLSKLTLRYYYTVDGQKDQTFWCDHAAI } \\
\text { IGSNGSYNGITSNVKGTFVKMSSSTNNADTYLEISFTGGTLEPGAHVHIQGRFAKNDWSNYTQSNDYSFKSASQFVEWDQVT } \\
\text { PYLNGVLVWGKEP* }\end{array}$ \\
\hline
\end{tabular}


Table S4. Raw material expenses for protein production and purification. The prices do not include any instrumentation costs and labor costs. For biotinylated MBP-SsoNP.E1, $500 \mathrm{~mL}$ culture media yields 58.5 $\mathrm{mg}$ in one purification. For SsoNP.E2-CBD, $500 \mathrm{~mL}$ culture media yields $150 \mathrm{mg}$ in one purification. From the tables below, the calculated raw material prices of the proteins are $\$ 0.24 / \mathrm{mg}$ biotinylated MBPSsoNP.E1 and \$0.09/mg SsoNP.E2-CBD. For one test, $53 \mathrm{ng}$ of biotinylated MBP-SsoNP.E1 and $400 \mathrm{ng}$ of SsoNP.E2-CBD are used, so the raw material cost for protein per device is $\$ 0.00005$.

\begin{tabular}{|c|c|c|c|c|c|c|c|}
\hline \multicolumn{8}{|c|}{ Production (Liter-scale) } \\
\hline & Material & Vendor & Catalog \# & Usage per $L$ & unit & Price $(\$) / g, m g$, or $\mathrm{mL}$ & Price $(\$)$ per L \\
\hline \multirow{5}{*}{ TB buffer } & Tryptone & VWR & $90000-286$ & 12 & $\mathrm{~g}$ & 0.264 & 3.165 \\
\hline & $\begin{array}{c}\text { Bacto }^{T M} \text { Yeast } \\
\text { Extract }\end{array}$ & ThermoFisher Scientific & 212750 & 24 & $\mathrm{~g}$ & 0.224 & 5.376 \\
\hline & Glycerol & VWR & $97062-452$ & 4 & $\mathrm{ml}$ & 0.100 & 0.399 \\
\hline & $\mathrm{KH}_{2} \mathrm{PO}_{4}$ & Millipore Sigma & P0662-2.5KG & 2.3 & $\mathrm{~g}$ & 0.096 & 0.220 \\
\hline & $\mathrm{K}_{2} \mathrm{HPO}_{4}$ & WWR & $\mathrm{BDH} 0266-2.5 \mathrm{KG}$ & 12.54 & g & 0.149 & 1.874 \\
\hline & IPTG & Thermo Fisher Scientific & R0392 & 119 & $\mathrm{mg}$ & 0.040 & 4.736 \\
\hline & Biotin & Millipore Sigma & B4639-1G & 48 & $\mathrm{mg}$ & 0.156 & 7.488 \\
\hline Total & & & & & & & 23.258 \\
\hline \multicolumn{8}{|c|}{ Purification } \\
\hline & Material & vendor & catalog \# & $\begin{array}{l}\text { Usage per } \\
\text { purification }\end{array}$ & unit & Price $(\$) / g, m g$, or $\mathrm{mL}$ & Price (\$) per purification \\
\hline \multirow{3}{*}{$\begin{array}{c}\text { Equilibration buffer } \\
\text { (200mL per purification) }\end{array}$} & Tris & VWR & $97063-890$ & 1.211 & $\mathrm{~g}$ & 0.114 & 0.138 \\
\hline & $\mathrm{NaCl}$ & VWR & $97061-274$ & 3.506 & $\mathrm{~g}$ & 0.063 & 0.219 \\
\hline & Imidazole & VWR & $97064-622$ & 0.136 & $\mathrm{~g}$ & 0.547 & 0.074 \\
\hline \multirow{3}{*}{$\begin{array}{c}\text { Buffer B } \\
\text { (50mL per purification) }\end{array}$} & Tris & VWR & $97063-890$ & 0.303 & $\mathrm{~g}$ & 0.114 & 0.034 \\
\hline & $\mathrm{NaCl}$ & VWR & $97061-274$ & 0.877 & $\mathrm{~g}$ & 0.063 & 0.055 \\
\hline & Imidazole & VWR & $97064-622$ & 1.702 & $\mathrm{~g}$ & 0.547 & 0.930 \\
\hline Storage buffer & $10 \times P B S$ & VWR & EM-6505 & 10.000 & $\mathrm{~mL}$ & 0.067 & 0.673 \\
\hline Total & & & & & & & 2.123 \\
\hline
\end{tabular}

Table S5. Quantification of SARS-CoV-2 N-protein in inactivated virus samples using the Simoa SARSCoV-2 N Protein Antigen assay on the fully-automated Quanterix Analyzer. ${ }^{8}$

\begin{tabular}{|c|c|c|}
\hline Inactivation method & Gamma irradiated & Triton-inactivated \\
\hline Source & $\begin{array}{c}\text { NR-52287 } \\
\text { Lot } 70033322\end{array}$ & HS112520 \\
\hline $\mathrm{TCID}_{50} / \mathrm{mL}$ & $2.80 \times 10^{5}$ & \\
\hline PFU $/ \mathrm{mL}$ & & $2.50 \times 10^{6}$ \\
\hline $\begin{array}{c}\text { SARS-CoV-2 } \\
\text { N-protein }(\mathrm{nM})\end{array}$ & 116 & 17 \\
\hline
\end{tabular}




\section{Figures}

(A)

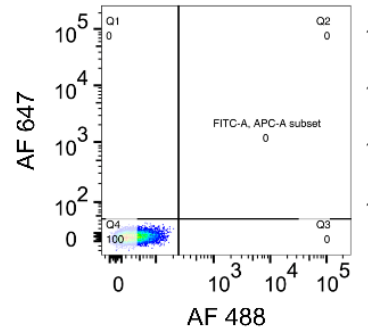

Negative control

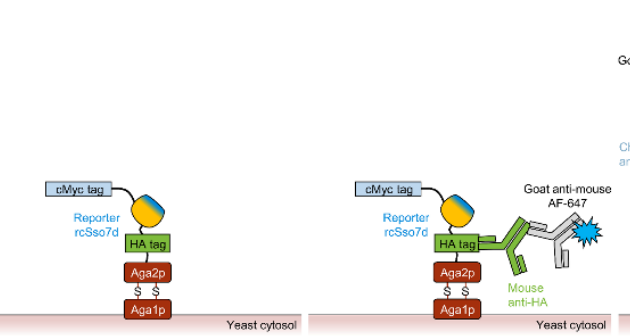

(C)

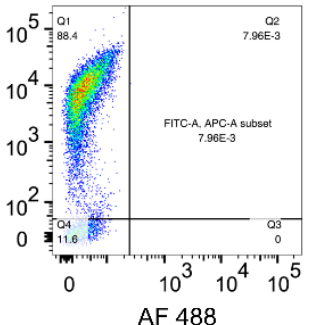

AF 488

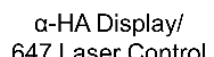

a-HA Display/
647 Laser Contro
(D)

(E)
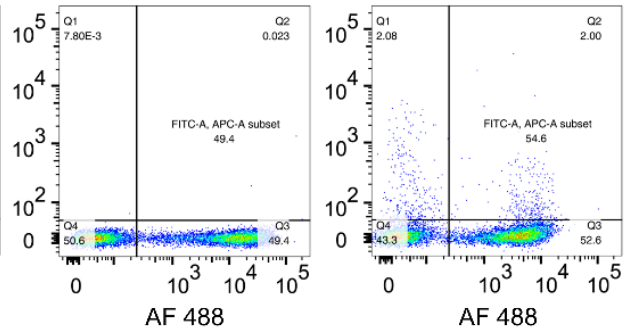

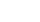
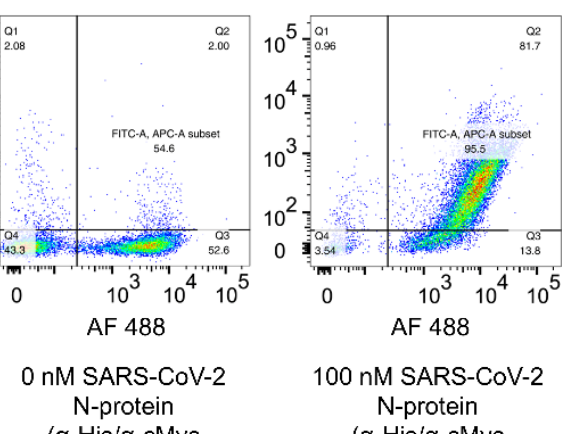

N-protein
(a-His/a-cMyc
Labeling)

100 nM SARS-CoV-2

$\mathrm{N}$-protein

(a-His/a-cMyc

Labeling)

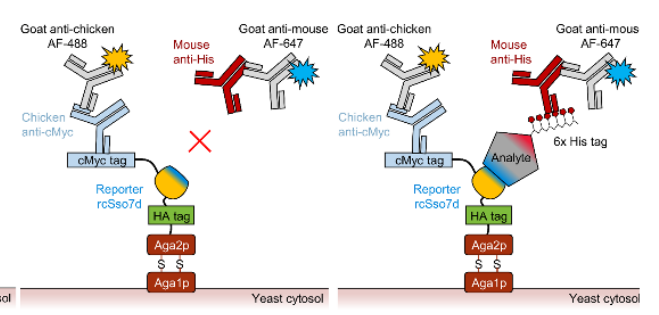

Figure S1. Detailed schematic of FACS for reporter binder selection against SARS-CoV-2 N-protein. rcSso7d proteins are expressed on the surface of yeast cells with flanking HA/cMyc tags. (A) Negative control. No target and fluorescent reagents are added. (B) rcSso7d display check with HA-tag. The yeast cells are incubated with anti-HA mouse antibody and AF 647-conjugated anti-mouse antibody. (C) rcSso7d display check with cMyc tag. The yeast cells are incubated with anti-cMyc chicken antibody and AF 488conjugated anti-chicken antibody. (D) Negative sorting. The yeast cells are incubated with anti-cMyc chicken antibody, AF 488-conjugated anti-chicken antibody, anti-His mouse antibody, and AF 647conjugated anti-mouse antibody. In this step, off-target binders are removed by selecting cells showing only cMyc-tag display signals (bottom right quarter). (E) Positive sorting. The yeast cells selected from the negative sorting are incubated with recombinant SARS-CoV-2 N-protein featuring N-terminal hexahistidine tags and all reagents used in negative sorting. Small portion (ex. 10\%) of cells showing high ratios of target binding signals (AF 647) to display signals (AF 488) are collected, and selection stringency is increased by reducing the percentage over multiple rounds, and subsequently reducing the target concentration from $100 \mathrm{nM}$ to $1 \mathrm{nM}$. 
(A)

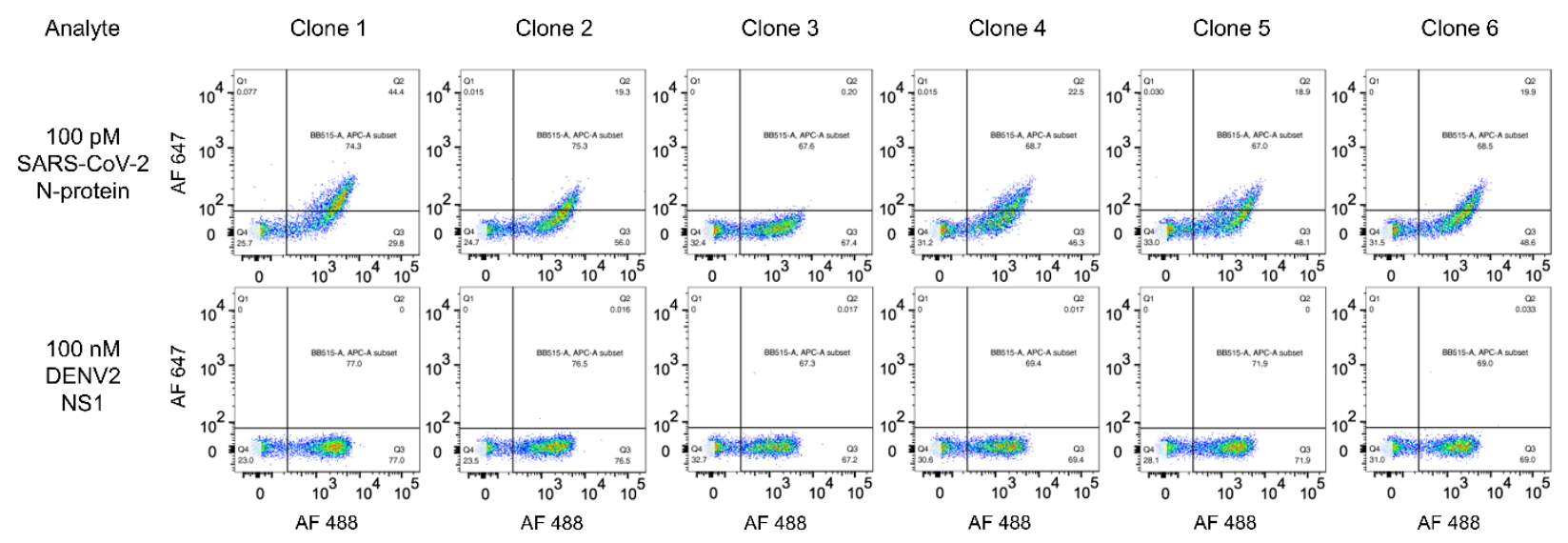

(B)

\begin{tabular}{ccccc}
\hline Geometric mean & 100 pM N-protein (S) & 100 nM DENV2 NS1 (NS) & S-NS & S/NS \\
\hline Clone 1 & 89.1 & 9.84 & 79.3 & 9.1 \\
Clone 2 & 50.8 & 11.6 & 39.2 & 4.4 \\
Clone 3 & 16.3 & 9.61 & 6.7 & 1.7 \\
Clone 4 & 58.2 & 9.79 & 48.4 & 5.9 \\
Clone 5 & 52 & 9.51 & 42.5 & 5.5 \\
Clone 6 & 55.7 & 9.85 & 45.9 & 5.6
\end{tabular}

Figure S2. Evaluation of the selected reporter binder (Reporter rcSso7d) clones. (A) FACS plots of the clones with and without the target (SARS-CoV-2 N-protein). With 100 pM SARS-CoV-2 N-protein, all of the selected clones show binding signals (in top right quarter). A non-specific target, dengue virus serotype 2 non-structural protein 1 (DENV2 NS1), cannot yield specific binding signals from any of the clones even at $100 \mathrm{nM}$. (B) Geometric mean fluorescence intensity from AF 647 for each clone incubated with $100 \mathrm{pM}$ SARS-CoV-2 N-protein (specific target, S) or 100 nM DENV2 NS1 (non-specific target, NS). The clone 1 provided a higher background-subtracted signal (S-NS) and a higher ratio (S/NS) of specific binding signals to non-specific binding signals than any other selected clones. 


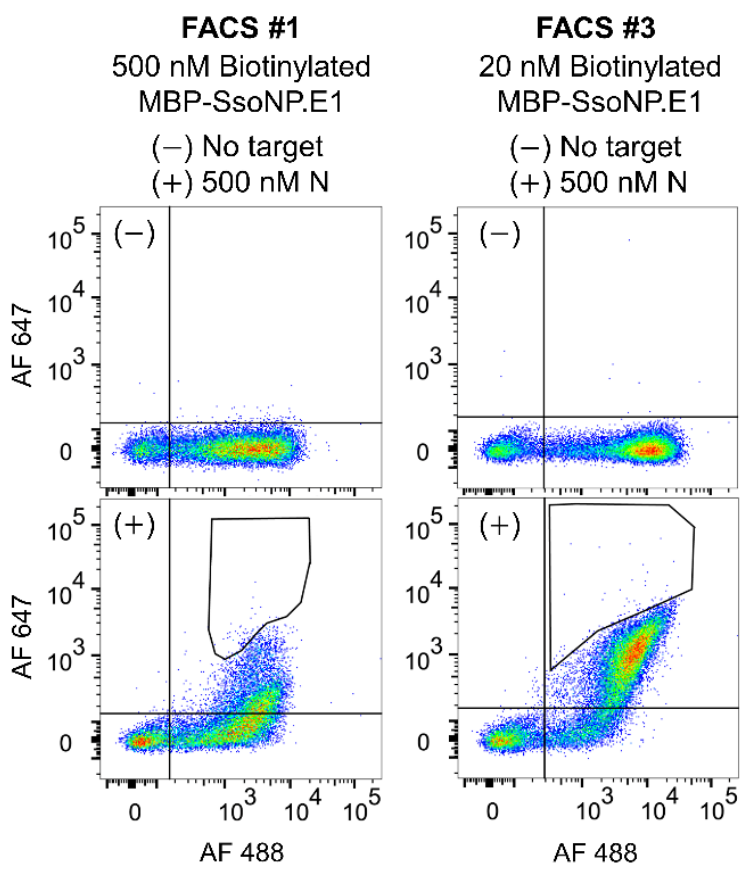

Figure S3. Representative FACS plots for selection of the capture binder SsoNP.E2-1 against SARS-CoV$2 \mathrm{~N}$-protein from FACS \#1 and FACS \#3. Gates drawn indicate the gates used for sorting. The yeast library obtained from two rounds of FACS for reporter binder selection was sorted with biotinylated MBPSsoNP.E1 and streptavidin-AF647 labeling. To minimize enrichment of affinity reagents that cross-react with MBP-SsoNP.E1, the concentration of the primary affinity reagent was reduced from $500 \mathrm{nM}$ to $20 \mathrm{nM}$ in these rounds. 


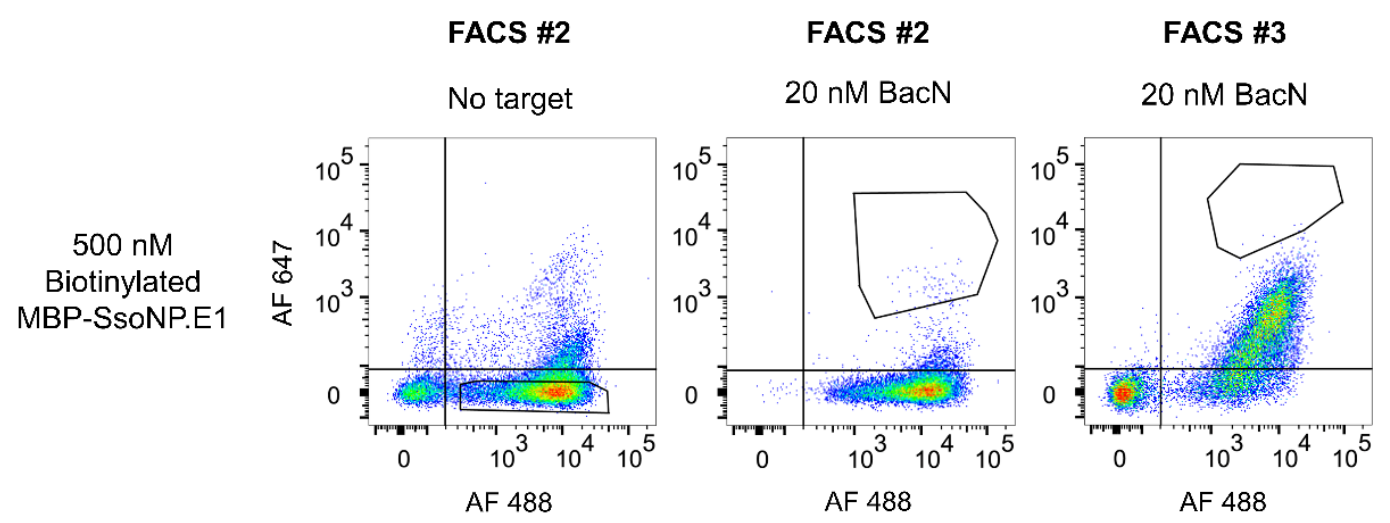

Figure S4. Representative FACS plots for selection of the capture binders SsoNP.E2-2 and SsoNP.E2-3 against baculovirus-produced SARS-CoV-1 N-protein (BacN) from FACS \#2 and FACS \#3. Gates drawn indicate the gates used for sorting. The yeast library obtained from two rounds of magnetic bead sorting (MBS) for reporter binder selection was sorted with biotinylated MBP-SsoNP.E1 and streptavidin-AF647 labeling. Because of the greater diversity of the post-MBS rcSso7d variants, a negative sort (FACS \#2) was done prior to a positive sort (FACS \#2) to remove non-specific binders. Having used the secondary FACS to enrich specific binding variants to a secondary epitope, we applied additional selective pressure for highaffinity, complementary capture binders with FACS \#3. 
(A)

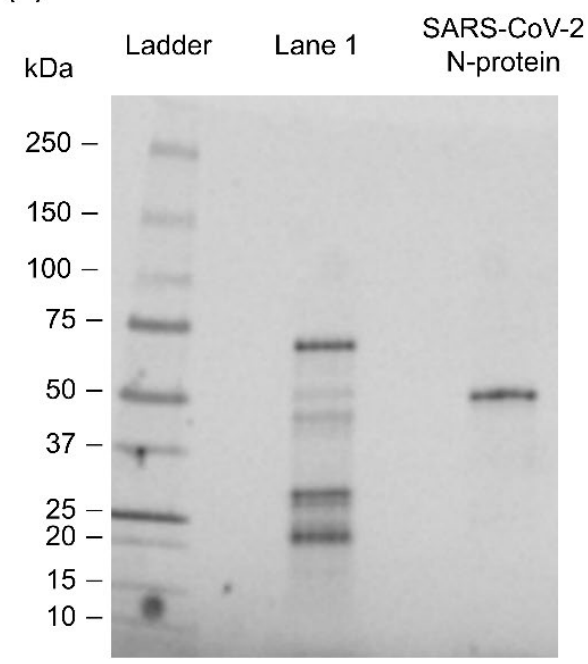

(B)

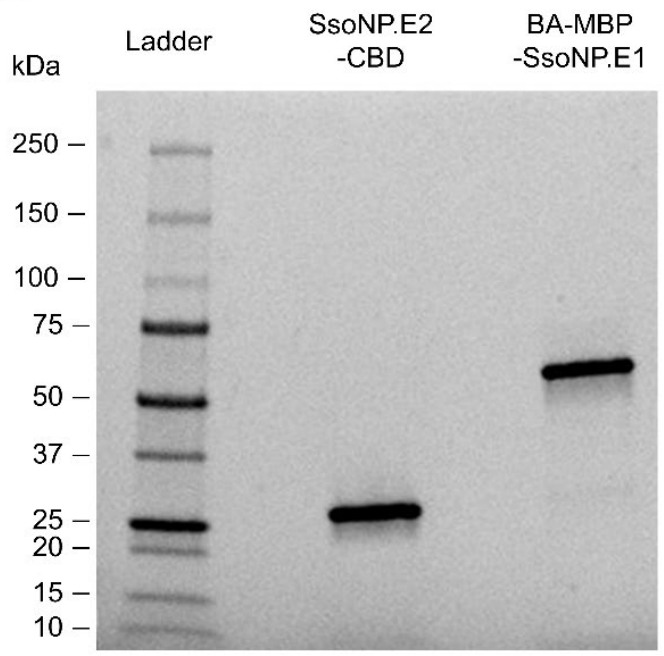

Figure S5. SDS-PAGE gel images of purified recombinant products. (A) SARS-CoV-2 N-protein band is observed near $47 \mathrm{kDa}$. Lane 1 corresponds to crude CBD-N-protein fusion products not considered in this work. (B) SsoNP.E2-CBD and biotinylated (or BA-)MBP-SsoNP.E1 bands appear at their theoretical molecular weight (28 kDa and $54 \mathrm{kDa}$, respectively). 
(A)

BA-MBP-SsoNP.E1 with N-protein

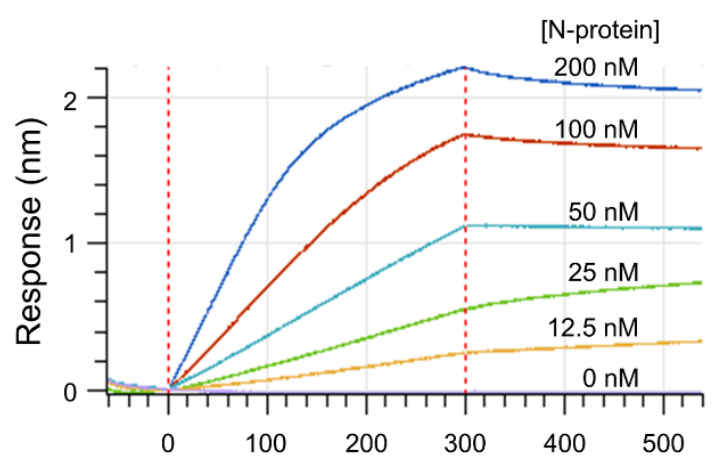

(B)

SsoNP.E2-CBD with N-protein

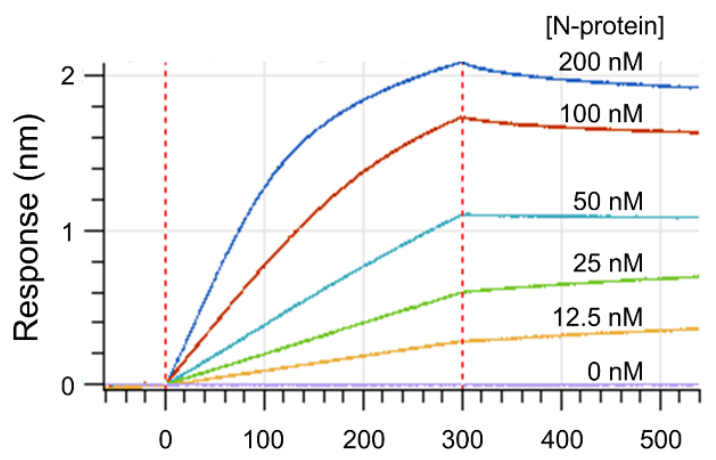

(C)

\begin{tabular}{ccccccccc}
\hline Loading Sample ID & Association Sample ID & $\mathrm{Kd}(\mathrm{M})$ & $\mathrm{Kd} \operatorname{Error}(\mathrm{M})$ & $\mathrm{k}_{\text {on }}\left(\mathrm{M}^{-1} \mathrm{~s}^{-1}\right)$ & $\mathrm{k}_{\text {on }} \operatorname{Error}\left(\mathrm{M}^{-1} \mathrm{~s}^{-1}\right)$ & $\mathrm{k}_{\text {off }}\left(\mathrm{s}^{-1}\right)$ & $\mathrm{k}_{\text {off }} \operatorname{Error}_{\left(\mathrm{s}^{-1}\right)}$ \\
\hline BA-MBP-SsoNP.E1 & SARS-CoV-2 N-protein & $3.24 \mathrm{E}-09$ & $1.47 \mathrm{E}-10$ & $3.59 \mathrm{E}+04$ & $1.72 \mathrm{E}+02$ & $1.16 \mathrm{E}-04$ & $5.24 \mathrm{E}-06$ \\
& & & & & & & \\
SsoNP.E2-CBD & SARS-CoV-2 N-protein & $4.42 \mathrm{E}-09$ & $9.98 \mathrm{E}-11$ & $3.94 \mathrm{E}+04$ & $1.34 \mathrm{E}+02$ & $1.74 \mathrm{E}-04$ & $3.89 \mathrm{E}-06$
\end{tabular}

Figure S6. Bio-layer interferometry (BLI) curves for kinetic analysis of SARS-CoV-2 N-protein affinity reagents. Kinetic analysis was conducted with ForteBio's Octet RED96 Bio-Layer Interferometry platform, using Penta-HIS (HIS1K) sensor tips. Sample concentrations were assessed using a BCA assay and adjusted to the desired concentrations using kinetics buffer $(1 \times \mathrm{PBS}, 0.1 \% \mathrm{w} / \mathrm{v}$ BSA, and $0.02 \% \mathrm{v} / \mathrm{v}$ Tween-20). PentaHis-coated BLI sensors were hydrated in kinetics buffer for ten minutes with shaking on plate shaker at room temperature. All wells were filled with a $200 \mu \mathrm{L}$ solution volume and all steps were performed at $25{ }^{\circ} \mathrm{C}$ with mixing at $1000 \mathrm{rpm}$. Evaluation of binding kinetic parameters was initiated by incubating the pre-hydrated HIS1K tip first in kinetics buffer to obtain a signal baseline (60 seconds). Next the tips were contacted with the ligand solution which contains either (A) Biotinylated (or BA-)MBP-SsoNP.E1 or (B) SsoNP.E2-CBD with molar concentration of $200 \mathrm{nM}$ for 60 seconds. After another baseline incubation in the kinetics buffer (60 seconds), the tips were contacted with the association partner (SARS-CoV-2 Nprotein without $6 \times$ His-tag) for the association step (300 seconds) before incubation in kinetics buffer for the dissociation step (240 seconds). Two-fold serial dilutions of the tagless SARS-CoV-2 N-protein (from $200 \mathrm{nM}$ to $12.5 \mathrm{nM}$ ) were tested so as to measure multiple binding curves for more reliable kinetic parameters. (C) Obtained kinetic parameters from the BLI measurements. 
(A)

Front Back

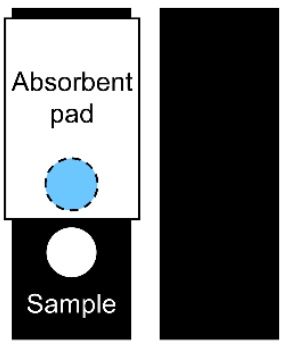

Design \#1

(C)

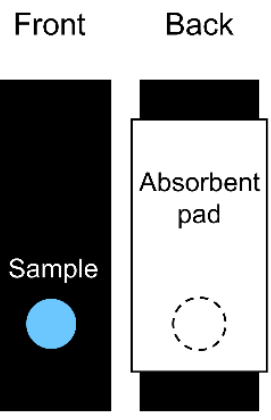

(B)
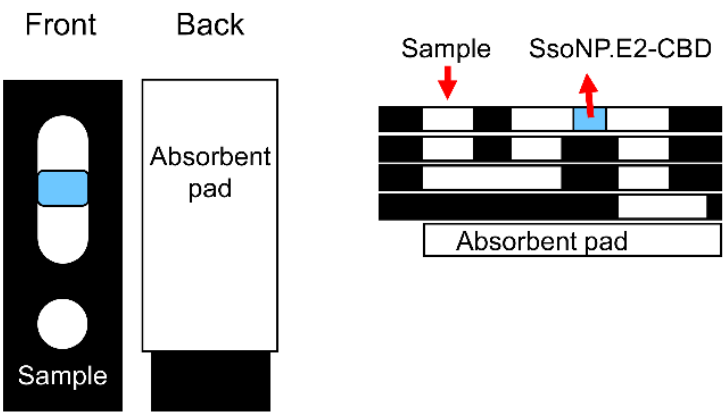

SsoNP.E2-CBD

(D)

Front Back
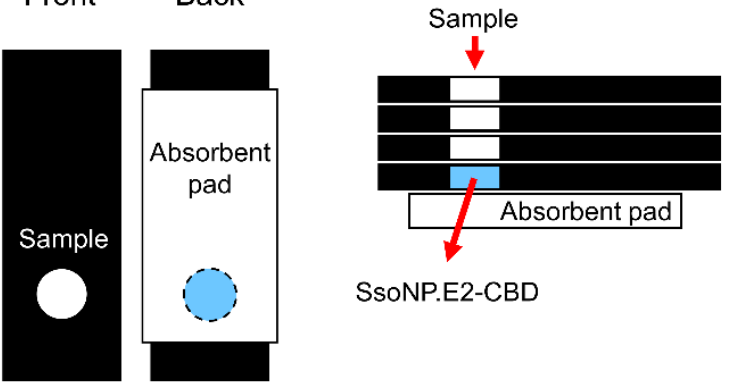

SsoNP.E2-CBD

Design \#3

Design \#4

Figure S7. Microfluidic device designs assessed in the study. (A) Design \#1. Sample flows through vertical and lateral flow channels while interacting with reagents (biotinylated MBP-SsoNP.E1 and streptavidinHRP), and comes back to front side test zone where SsoNP.E2-CBD is immobilized. Absorbent pad is removed to check the test result. (B) Design \#2. Sample flows through vertical and lateral flow channels while interacting with the reagents. N-protein-enzyme complex will be captured by SsoNP.E2-CBD on the front side lateral flow channel. Absorbent pad is not removed for checking the result. (C) Design \#3. Premixed solution of sample and the reagents flows through the vertical flow channel. N-protein-enzyme complex will be specifically bound to the test zone on the top layer. Absorbent pad is not removed for checking the result. (D) Design \#4. Sample flows through the vertical flow channel with the reagents. Nprotein-enzyme complex will be captured by SsoNP.E2-CBD on the bottom layer test zone. To check the result, absorbent pad should be removed. 
(A)

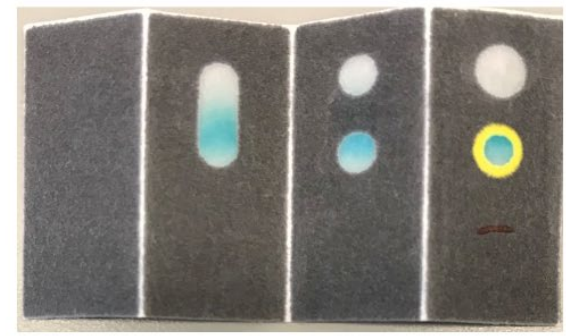

Design \#1

(C)

[SARS-CoV-2] (x10 $\mathrm{PFU} / \mathrm{mL})$

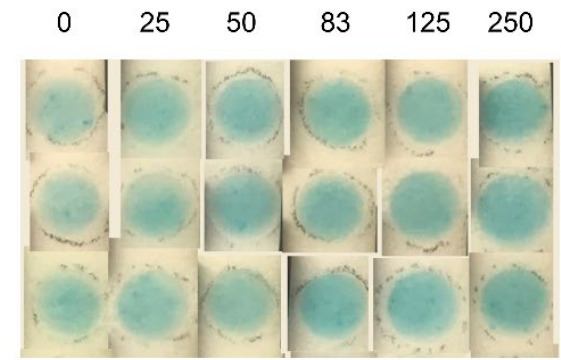

Design \#3
(B)

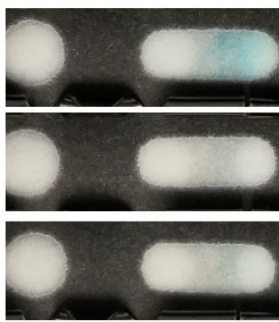

[SA-HRP] $=100 \mathrm{pM}$

$0 \mathrm{nM} \mathrm{N}$-protein

$[\mathrm{SA}-\mathrm{HRP}]=20 \mathrm{pM}$

$0 \mathrm{nM} \mathrm{N}$-protein

$[\mathrm{SA}-\mathrm{HRP}]=20 \mathrm{pM}$

$100 \mathrm{nM} N$-protein

Design \#2

(D)

[SARS-CoV-2] ( $\left.\times 10^{3} \mathrm{PFU} / \mathrm{mL}\right)$

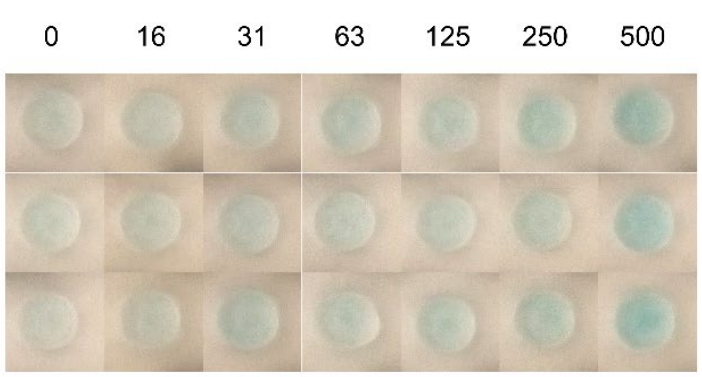

Design \#4

Figure S8. Evaluating various designs of $\mu$ PADs. All designs were tested on Whatman No. 1 or equivalent grade cellulose paper. Hydrophobic barriers on initial tests (A, B) with Designs \#1 and \#2 were created with solid wax ink. For later tests with the vertical flow formats (C, D), UV-curable resin was used to create the hydrophobic barriers. (A) Design \#1. The image shows the assay result with $0 \mathrm{nM}$ N-protein. It seems that the reagents (biotinylated MBP-SsoNP.E1 and streptavidin-HRP) get stuck on the junction of a lateral flow channel and a vertical flow channel due to the decrease in linear flow velocity ( $v_{\text {vertical }}=$ $\frac{A_{\text {Lateral }}}{A_{\text {Vertical }}} \times v_{\text {Lateral }}$ from volumetric flow rate $Q=A_{\text {Lateral }} \times v_{\text {Lateral }}=A_{\text {Vertical }} \times v_{\text {Vertical }}$ and $\left.\frac{A_{\text {Lateral }}}{A_{\text {Vertical }}} \ll 1\right)$. (B) Design \#2. As shown in the first assay result, non-specific signals are generated at the lateral to vertical channel junction. If we lower the concentration of the enzyme to reduce the background signals, specific signals also decrease. (C) Design \#3. Compared to Designs \#1 and \#2, non-specific signals are reduced enough to detect cultured SARS-CoV-2 regardless of printing materials (wax and UV-curable resin). However, high variability in colorimetric signals was caused by spatially irregular flow rates on the top test zone. (D) Design \#4. In this bottom test zone format, the flow rates become much more uniform at the test zone than Design \#3, and large particles in sample can also be filtered while flowing through multi-layers of paper wells. With a lower standard deviation, the bottom readout format can achieve better limit of detection than Design \#3. 


\begin{tabular}{|c|c|c|c|c|c|c|c|c|}
\hline \multirow[b]{2}{*}{$\operatorname{Exp}$} & \multicolumn{3}{|c|}{ Diluent components } & \multicolumn{4}{|c|}{ CMYK Mean C Intensity } & \multirow[b]{6}{*}{ Poor } \\
\hline & [Phosphate] & {$[\mathrm{NaCl}]$} & {$[\mathrm{BSA}]$} & Non-specific (NS) & Specific (S) & $\mathrm{S} / \mathrm{NS}$ & S-NS & \\
\hline 1 & $50 \mathrm{mM}$ & $0 \mathrm{mM}$ & $1 \%$ & 0.10 & 0.30 & 2.98 & 0.20 & \\
\hline 2 & $50 \mathrm{mM}$ & $0 \mathrm{mM}$ & $3 \%$ & 0.31 & 0.50 & 1.60 & 0.19 & \\
\hline 3 & $50 \mathrm{mM}$ & $0 \mathrm{mM}$ & $5 \%$ & 0.27 & 0.44 & 1.66 & 0.18 & \\
\hline 4 & $50 \mathrm{mM}$ & $50 \mathrm{mM}$ & $1 \%$ & 0.19 & 0.48 & 2.49 & 0.29 & \\
\hline 5 & $50 \mathrm{mM}$ & $50 \mathrm{mM}$ & $3 \%$ & 0.15 & 0.38 & 2.54 & 0.23 & \\
\hline 6 & $50 \mathrm{mM}$ & $50 \mathrm{mM}$ & $5 \%$ & 0.17 & 0.46 & 2.67 & 0.29 & \\
\hline 7 & $50 \mathrm{mM}$ & $150 \mathrm{mM}$ & $1 \%$ & 0.17 & 0.46 & 2.63 & 0.28 & \\
\hline 8 & $50 \mathrm{mM}$ & $150 \mathrm{mM}$ & $3 \%$ & 0.19 & 0.45 & 2.41 & 0.26 & \\
\hline 9 & $50 \mathrm{mM}$ & $150 \mathrm{mM}$ & $5 \%$ & 0.19 & 0.52 & 2.77 & 0.33 & \\
\hline 10 & $200 \mathrm{mM}$ & $0 \mathrm{mM}$ & $1 \%$ & 0.22 & 0.60 & 2.72 & 0.38 & \\
\hline 11 & $200 \mathrm{mM}$ & $0 \mathrm{mM}$ & $3 \%$ & 0.18 & 0.58 & 3.23 & 0.40 & \\
\hline 12 & $200 \mathrm{mM}$ & $0 \mathrm{mM}$ & $5 \%$ & 0.17 & 0.55 & 3.29 & 0.38 & \\
\hline 13 & $200 \mathrm{mM}$ & $50 \mathrm{mM}$ & $1 \%$ & 0.19 & 0.58 & 3.03 & 0.39 & Good \\
\hline 14 & $200 \mathrm{mM}$ & $50 \mathrm{mM}$ & $3 \%$ & 0.15 & 0.57 & 3.74 & 0.41 & \\
\hline 15 & $200 \mathrm{mM}$ & $50 \mathrm{mM}$ & $5 \%$ & 0.18 & 0.59 & 3.25 & 0.41 & \\
\hline 16 & $200 \mathrm{mM}$ & $150 \mathrm{mM}$ & $1 \%$ & 0.17 & 0.57 & 3.46 & 0.41 & \\
\hline 17 & $200 \mathrm{mM}$ & $150 \mathrm{mM}$ & $3 \%$ & 0.12 & 0.59 & 4.80 & 0.47 & \\
\hline 18 & $200 \mathrm{mM}$ & $150 \mathrm{mM}$ & $5 \%$ & 0.10 & 0.56 & 5.85 & 0.47 & \\
\hline
\end{tabular}

Figure S9. Optimization of saliva assays - diluent components. Paper-based assays are prepared by preimmobilizing SsoNP.E2-CBD $(30 \mu \mathrm{M}, 0.5 \mu \mathrm{L})$ on test zones on the fourth layer and blocking all wells with $1 \mathrm{w} / \mathrm{v} \% \mathrm{BSA}$ in $1 \times \mathrm{PBS}(1 \mu \mathrm{L})$. The condition $18(200 \mathrm{mM}$ phosphate, $150 \mathrm{mM} \mathrm{NaCl}$, and $5 \mathrm{w} / \mathrm{v} \% \mathrm{BSA})$ provided the highest $\mathrm{S} / \mathrm{NS}$ and $\mathrm{S}-\mathrm{NS}$. Higher concentrations of phosphate and $\mathrm{NaCl}$ did not improve the assay performance, so we decided to use this condition for diluent.

Protocol (variable for optimization and range highlighted in red): Freshly prepare reagent solution including $200 \mathrm{nM}$ BA-MBP-SsoNP.E1 and $50 \mathrm{ng} / \mathrm{mL}$ streptavidin-HRP in diluent (50 or $200 \mathrm{mM}$ phosphate pH 6 buffer including $0-150 \mathrm{mM} \mathrm{NaCl}$ and 1-5\% BSA). Add the prepared reagent solution (10 $\mu \mathrm{L})$ to positive saliva sample $(1 \mathrm{v} / \mathrm{v} \%$ Triton X-100 included, $10 \mu \mathrm{L})$ including $100 \mathrm{nM}$ SARS-CoV-2 N-protein and negative saliva sample $(1 \mathrm{v} / \mathrm{v} \%$ Triton X-100 included, $10 \mu \mathrm{L})$ without the N-protein. Apply $20 \mu \mathrm{L}$ of the positive and negative control solutions to assembled vertical flow assays and wash with $1 \mathrm{w} / \mathrm{v} \% \mathrm{BSA}$ in $1 \times$ PBS $(50 \mu \mathrm{L})$. Flip the devices, remove wicking pads, and add $10 \mu \mathrm{L}$ of TMB substrate solution. Image the test zones after 3-min color development. 


\begin{tabular}{|c|c|c|c|c|c|c|c|}
\hline \multicolumn{3}{|c|}{ Diluent and washing buffer } & \multicolumn{4}{|c|}{ CMYK Mean C Intensity } & \multirow{4}{*}{ Poor } \\
\hline Exp & Detergent & Concentration & Non-specific (NS) & Specific (S) & $\mathrm{S} / \mathrm{NS}$ & S-NS & \\
\hline 1 & No & $0 \%$ & 0.170 & 0.722 & 4.247 & 0.552 & \\
\hline 2 & No & $0 \%$ & 0.247 & 0.687 & 2.781 & 0.440 & \\
\hline 3 & Tween-20 & $0.05 \%$ & 0.142 & 0.677 & 4.768 & 0.535 & \\
\hline 4 & Tween-20 & $0.10 \%$ & 0.156 & 0.671 & 4.301 & 0.515 & \\
\hline 5 & Tween-20 & $0.50 \%$ & 0.168 & 0.725 & 4.315 & 0.557 & \\
\hline 6 & Tween-20 & $1 \%$ & 0.105 & 0.621 & 5.914 & 0.516 & \\
\hline 7 & Triton X-100 & $0.05 \%$ & 0.178 & 0.696 & 3.910 & 0.518 & \\
\hline 8 & Triton X-100 & $0.10 \%$ & 0.168 & 0.723 & 4.304 & 0.555 & \\
\hline 9 & Triton X-100 & $0.50 \%$ & 0.244 & 0.784 & 3.213 & 0.540 & \\
\hline 10 & CHAPS & $0.05 \%$ & 0.148 & 0.678 & 4.581 & 0.530 & \\
\hline 11 & CHAPS & $0.10 \%$ & 0.137 & 0.743 & 5.423 & 0.606 & \\
\hline 12 & CHAPS & $0.50 \%$ & 0.067 & 0.653 & 9.746 & 0.586 & \\
\hline 13 & CHAPS & $1 \%$ & 0.037 & 0.408 & 11.027 & 0.371 & \\
\hline
\end{tabular}

Figure S10. Optimization of saliva assays - diluent and washing buffer components. Paper-based assays are prepared by pre-immobilizing SsoNP.E2-CBD $(30 \mu \mathrm{M}, 0.5 \mu \mathrm{L})$ on test zones on the fourth layer and blocking all wells with $1 \mathrm{w} / \mathrm{v} \%$ BSA in $1 \times \mathrm{PBS}(1 \mu \mathrm{L})$. The condition $12(0.5 \mathrm{w} / \mathrm{v} \%$ CHAPS addition to the diluent) provided relatively high S/NS and S-NS simultaneously, so we decided to use this condition for diluent and washing buffer.

Protocol (variable for optimization and range highlighted in red): Freshly prepare reagent solution including $200 \mathrm{nM}$ BA-MBP-SsoNP.E1 and $50 \mathrm{ng} / \mathrm{mL}$ streptavidin-HRP in diluent (200 mM phosphate pH 6 buffer including $150 \mathrm{mM} \mathrm{NaCl}, 5 \mathrm{w} / \mathrm{v} \% \mathrm{BSA}$, and $0-1 \mathrm{v} / \mathrm{v} \%$ detergents). Add the prepared reagent solution (10 $\mu \mathrm{L})$ to positive saliva sample ( $1 \mathrm{v} / \mathrm{v} \%$ Triton X-100 included, $10 \mu \mathrm{L})$ including $100 \mathrm{nM}$ SARS-CoV-2 Nprotein and negative saliva sample ( $1 \mathrm{v} / \mathrm{v} \%$ Triton X-100 included, $10 \mu \mathrm{L})$ without the N-protein. Apply $20 \mu \mathrm{L}$ of the positive and negative control solutions to assembled vertical flow assays and wash with the diluent $(50 \mu \mathrm{L})$. Flip the devices, remove wicking pads, and add $10 \mu \mathrm{L}$ of TMB substrate solution. Image the test zones after 3-min color development. 


\begin{tabular}{|c|c|c|c|c|c|c|}
\hline & & \multicolumn{4}{|c|}{ CMYK Mean C Intensity } & \multirow[b]{4}{*}{ Poor } \\
\hline Exp & Blocking agents & Non-specific (NS) & Specific (S) & S/NS & S-NS & \\
\hline 1 & $0.5 \%$ casein blocker & 0.034 & 0.385 & 11.324 & 0.351 & \\
\hline 2 & $1 \% \mathrm{BSA}$ & 0.076 & 0.437 & 5.750 & 0.361 & \\
\hline 3 & $5 \%$ BSA & 0.216 & 0.592 & 2.741 & 0.376 & \\
\hline 4 & Western blot blocking buffer & 0.062 & 0.3 & 4.839 & 0.238 & \\
\hline 5 & Casamino acids & 0.137 & 0.463 & 3.380 & 0.326 & \\
\hline 6 & Peptone & 0.128 & 0.444 & 3.469 & 0.316 & \\
\hline 7 & Bacto Yeast Extract & 0.088 & 0.458 & 5.205 & 0.370 & \\
\hline 8 & $0.5 \%$ casein blocker & 0.034 & 0.374 & 11.000 & 0.340 & \\
\hline 9 & $1 \% \mathrm{BSA}$ & 0.112 & 0.538 & 4.804 & 0.426 & \\
\hline 10 & $5 \%$ BSA & 0.18 & 0.528 & 2.933 & 0.348 & \\
\hline 11 & Western blot blocking buffer & 0.065 & 0.332 & 5.108 & 0.267 & Good \\
\hline 12 & Casamino acids & 0.165 & 0.422 & 2.558 & 0.257 & \\
\hline 13 & Peptone & 0.198 & 0.483 & 2.439 & 0.285 & \\
\hline 14 & Bacto Yeast Extract & 0.151 & 0.467 & 3.093 & 0.316 & \\
\hline
\end{tabular}

Figure S11. Optimization of saliva assays - blocking agent. Paper-based assays are prepared by preimmobilizing SsoNP.E2-CBD $(30 \mu \mathrm{M}, 0.5 \mu \mathrm{L})$ on test zones on the fourth layer and blocking all wells with blocking agent $(1 \mu \mathrm{L})$. The condition $1,8(0.5 \mathrm{w} / \mathrm{v} \%$ casein blocker $5 \mathrm{w} / \mathrm{v} \%$ sucrose $0.1 \mathrm{v} / \mathrm{v} \%$ Tween-20 $150 \mathrm{mM} \mathrm{NaCl}$ in $0.1 \mathrm{M}$ phosphate buffer ( $\mathrm{pH}$ 6.3)) provided the highest $\mathrm{S} / \mathrm{NS}$ and relatively high $\mathrm{S}-\mathrm{NS}$, so we decided to use this blocking agent.

Protocol (variable for optimization and range highlighted in red): Freshly prepare reagent solution including $200 \mathrm{nM}$ BA-MBP-SsoNP.E1 and $50 \mathrm{ng} / \mathrm{mL}$ streptavidin-HRP in diluent (200 mM phosphate $\mathrm{pH} 6$ buffer including $150 \mathrm{mM} \mathrm{NaCl}, 5 \mathrm{w} / \mathrm{v} \% \mathrm{BSA}$, and $0.5 \mathrm{w} / \mathrm{v} \%$ CHAPS). Add the prepared reagent solution (10 $\mu \mathrm{L})$ to positive saliva sample ( $1 \mathrm{v} / \mathrm{v} \%$ Triton X-100 included, $10 \mu \mathrm{L})$ including $100 \mathrm{nM}$ SARS-CoV-2 Nprotein and negative saliva sample $(1 \mathrm{v} / \mathrm{v} \%$ Triton X-100 included, $10 \mu \mathrm{L})$ without the N-protein. Apply $20 \mu \mathrm{L}$ of the positive and negative control solutions to assembled vertical flow assays and wash with the diluent $(50 \mu \mathrm{L})$. Flip the devices, remove wicking pads, and add $10 \mu \mathrm{L}$ of TMB substrate solution. Image the test zones after 3-min color development. 


\begin{tabular}{|c|c|c|c|c|c|c|c|}
\hline \multirow[b]{2}{*}{ Exp } & \multicolumn{2}{|c|}{ Reagents } & \multicolumn{4}{|c|}{ CMYK Mean C Intensity } & \multirow[b]{4}{*}{ Poor } \\
\hline & [SsoNP.E2-CBD] & [BA-MBP-SsoNP.E1] & Non-specific (NS) & Specific (S) & S/NS & S-NS & \\
\hline 1 & $30 \mathrm{uM}$ & $100 \mathrm{nM}$ & 0.058 & 0.601 & 10.362 & 0.543 & \\
\hline 2 & $30 \mathrm{uM}$ & $50 \mathrm{nM}$ & 0.046 & 0.577 & 12.543 & 0.531 & \\
\hline 3 & $30 \mathrm{uM}$ & $20 \mathrm{nM}$ & 0.032 & 0.407 & 12.719 & 0.375 & \\
\hline 4 & $30 \mathrm{uM}$ & $10 \mathrm{nM}$ & 0.076 & 0.179 & 2.355 & 0.103 & \\
\hline 5 & $65 \mathrm{uM}$ & $100 \mathrm{nM}$ & 0.104 & 0.696 & 6.692 & 0.592 & \\
\hline 6 & $65 \mathrm{uM}$ & $50 \mathrm{nM}$ & 0.064 & 0.644 & 10.063 & 0.580 & \\
\hline 7 & $65 \mathrm{uM}$ & $20 \mathrm{nM}$ & 0.042 & 0.428 & 10.190 & 0.386 & \\
\hline 8 & $65 \mathrm{uM}$ & $10 \mathrm{nM}$ & 0.062 & 0.154 & 2.484 & 0.092 & \\
\hline 9 & $100 \mathrm{uM}$ & $100 \mathrm{nM}$ & 0.082 & 0.725 & 8.841 & 0.643 & \\
\hline 10 & $100 \mathrm{uM}$ & $50 \mathrm{nM}$ & 0.071 & 0.685 & 9.648 & 0.614 & \\
\hline 11 & $100 \mathrm{uM}$ & $20 \mathrm{nM}$ & 0.070 & 0.453 & 6.471 & 0.383 & Good \\
\hline 12 & $100 \mathrm{uM}$ & $10 \mathrm{nM}$ & 0.080 & 0.179 & 2.238 & 0.099 & \\
\hline
\end{tabular}

Figure S12. Optimization of saliva assays - binder concentrations. Paper-based assays are prepared by preimmobilizing SsoNP.E2-CBD (30-100 $\mu \mathrm{M}, 0.5 \mu \mathrm{L})$ on test zones on the fourth layer and blocking all wells with $0.5 \mathrm{w} / \mathrm{v} \%$ casein blocker $5 \mathrm{w} / \mathrm{v} \%$ sucrose $0.1 \mathrm{v} / \mathrm{v} \%$ Tween-20 $150 \mathrm{mM} \mathrm{NaCl}$ in $0.2 \mathrm{M}$ phosphate buffer ( $\mathrm{pH}$ 6.3) $(1 \mu \mathrm{L})$. The condition $2(30 \mu \mathrm{M}$ SsoNP.E2-CBD and $50 \mathrm{nM}$ BA-MBP-SsoNP.E1 in final concentration) provided relatively high S/NS and S-NS simultaneously, so we decided to use the condition 2 for binder concentrations.

Protocol (variable for optimization and range highlighted in red): Freshly prepare reagent solution including 20-200 nM BA-MBP-SsoNP.E1 and $50 \mathrm{ng} / \mathrm{mL}$ streptavidin-HRP in diluent (200 mM phosphate pH 6 buffer including $150 \mathrm{mM} \mathrm{NaCl}, 5 \mathrm{w} / \mathrm{v} \% \mathrm{BSA}$, and $0.5 \mathrm{w} / \mathrm{v} \% \mathrm{CHAPS})$. Add the prepared reagent solution $(10 \mu \mathrm{L})$ to positive saliva sample $(1 \mathrm{v} / \mathrm{v} \%$ Triton X-100 included, $10 \mu \mathrm{L})$ including $100 \mathrm{nM}$ SARS-CoV-2 $\mathrm{N}$-protein and negative saliva sample $(1 \mathrm{v} / \mathrm{v} \%$ Triton X-100 included, $10 \mu \mathrm{L})$ without the N-protein. Apply $20 \mu \mathrm{L}$ of the positive and negative control solutions to assembled vertical flow assays and wash with the diluent $(50 \mu \mathrm{L})$. Flip the devices, remove wicking pads, and add $10 \mu \mathrm{L}$ of TMB substrate solution. Image the test zones after 3-min color development. 
Diluent buffer

CMYK Mean C Intensity

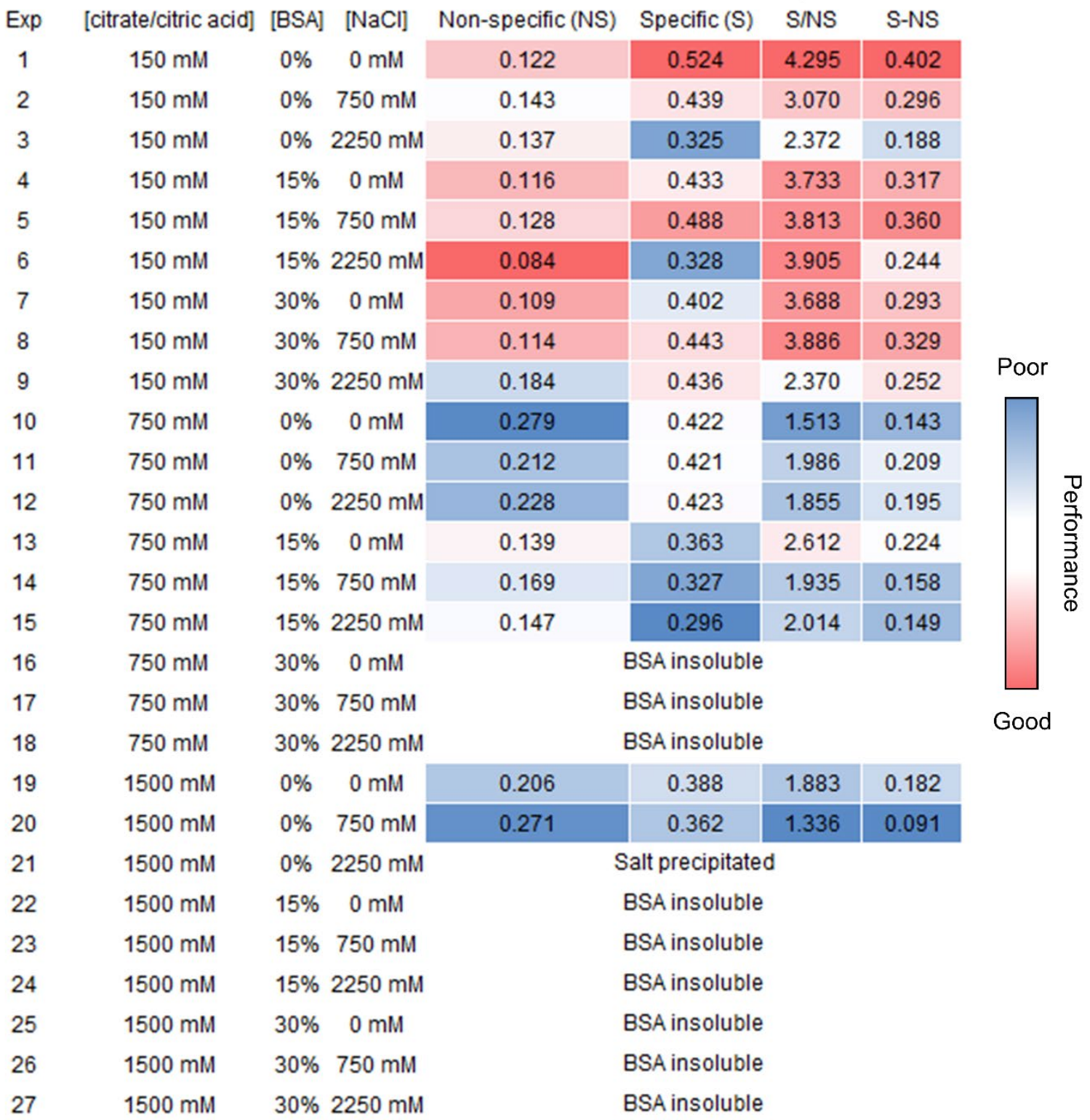

Figure S13. Optimization of simulated swab assays - diluent components. Paper-based assays are prepared by pre-immobilizing SsoNP.E2-CBD $(30 \mu \mathrm{M}, 0.5 \mu \mathrm{L})$ on test zones on the fourth layer and blocking all wells with $0.5 \mathrm{w} / \mathrm{v} \%$ casein blocker $5 \mathrm{w} / \mathrm{v} \%$ sucrose $0.1 \mathrm{v} / \mathrm{v} \%$ Tween-20 $150 \mathrm{mM} \mathrm{NaCl}$ in $0.1 \mathrm{M}$ phosphate buffer ( $\mathrm{pH}$ 6.3) $(1 \mu \mathrm{L})$. The condition $1(150 \mathrm{mM}$ citrate, $0 \mathrm{w} / \mathrm{v} \% \mathrm{BSA}$, and $0 \mathrm{mM} \mathrm{NaCl})$ provided the highest S/NS and S-NS, so we decided to use the condition 1 for the diluent. We used here citrate buffer instead of phosphate buffer because of low solubility of disodium phosphate at high buffer concentration $(>1 \mathrm{M})$, but we confirmed that $150 \mathrm{mM}$ phosphate buffer $(\mathrm{pH} \mathrm{6)}$ provided the same performance as 150 $\mathrm{mM}$ citrate buffer ( $\mathrm{pH}$ 6). In the following experiments, we used $150 \mathrm{mM}$ phosphate buffer ( $\mathrm{pH} 6$ ) as the diluent. 
Protocol (variable for optimization and range highlighted in red): Freshly prepare reagent solution including $750 \mathrm{nM}$ BA-MBP-SsoNP.E1 and $3 \mu \mathrm{g} / \mathrm{mL}$ neutravidin-HRP in pH 6 diluent including 150-1500 mM citrate, 0-30 w/v \% BSA, and 0-2250 mM NaCl. Add the prepared reagent solution ( $1 \mu \mathrm{L})$ to positive simulated swab sample $(1 \mathrm{v} / \mathrm{v} \%$ Triton $\mathrm{X}-100$ treated $1 \times \mathrm{PBS}, 14 \mu \mathrm{L})$ including $5 \mathrm{nM}$ SARS-CoV-2 N-protein and negative simulated swab sample $(1 \mathrm{v} / \mathrm{v} \%$ Triton X-100 treated $1 \times \mathrm{PBS}, 14 \mu \mathrm{L})$ without the N-protein. Apply $15 \mu \mathrm{L}$ of the positive and negative control solutions to assembled vertical flow assays and wash with the washing buffer (200 mM phosphate pH 6 buffer including $150 \mathrm{mM} \mathrm{NaCl}, 5 \mathrm{w} / \mathrm{v} \% \mathrm{BSA}$, and $0.5 \mathrm{w} / \mathrm{v} \%$ CHAPS, $50 \mu \mathrm{L}$ ). Flip the devices, remove wicking pads, and add $10 \mu \mathrm{L}$ of TMB substrate solution. Image the test zones after 3-min color development. 


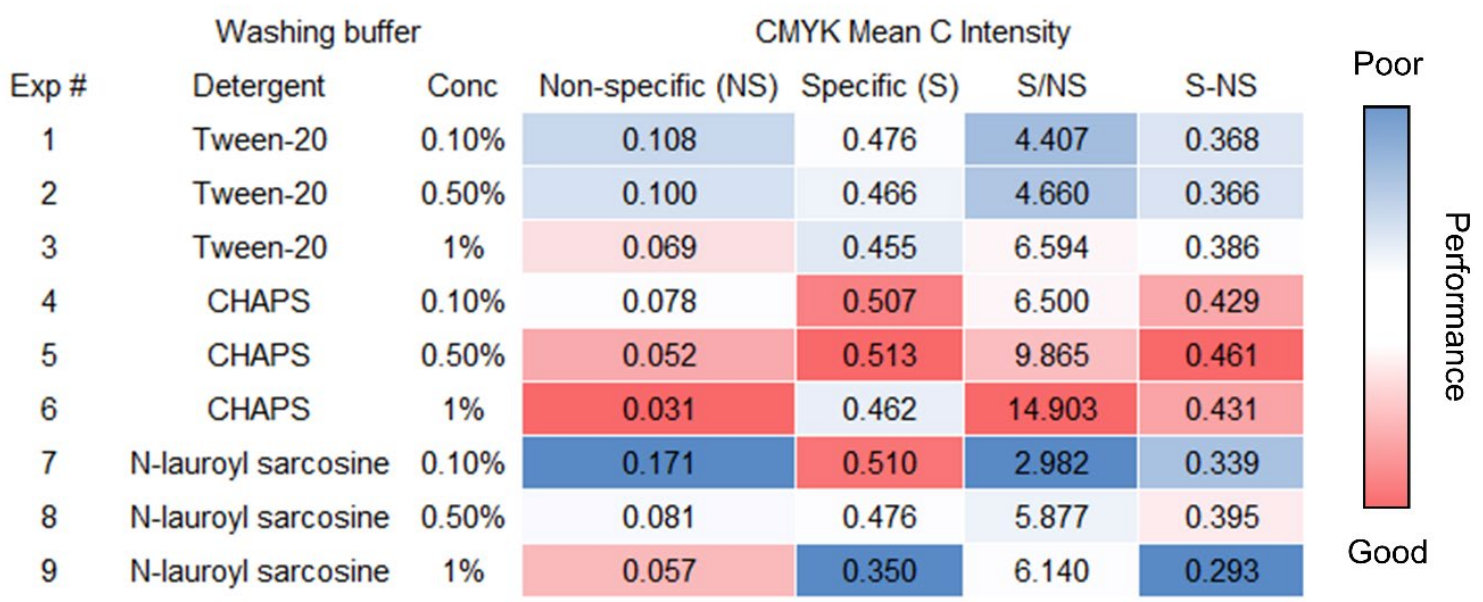

Figure S14. Optimization of simulated swab assays - washing buffer components. Paper-based assays are prepared by pre-immobilizing SsoNP.E2-CBD $(30 \mu \mathrm{M}, 0.5 \mu \mathrm{L})$ on test zones on the fourth layer and blocking all wells with $0.5 \mathrm{w} / \mathrm{v} \%$ casein blocker $5 \mathrm{w} / \mathrm{v} \%$ sucrose $0.1 \mathrm{v} / \mathrm{v} \%$ Tween-20 $150 \mathrm{mM} \mathrm{NaCl}$ in $0.1 \mathrm{M}$ phosphate buffer $(\mathrm{pH} 6.3)(1 \mu \mathrm{L})$. The condition $6(1 \mathrm{w} / \mathrm{v} \%$ CHAPS addition to washing buffer) provided the highest S/NS and relatively high S-NS, so we decided to use the condition 6 for the washing buffer.

Protocol (variable for optimization and range highlighted in red): Freshly prepare reagent solution including $750 \mathrm{nM}$ BA-MBP-SsoNP.E1 and $3 \mu \mathrm{g} / \mathrm{mL}$ neutravidin-HRP in $\mathrm{pH} 6$ diluent (150 mM phosphate buffer). Add the prepared reagent solution $(1 \mu \mathrm{L})$ to positive simulated swab sample $(1 \mathrm{v} / \mathrm{v} \%$ Triton $\mathrm{X}-100$ treated $1 \times$ PBS, $14 \mu \mathrm{L})$ including $5 \mathrm{nM}$ SARS-CoV-2 N-protein and negative simulated swab sample $(1 \mathrm{v} / \mathrm{v} \%$ Triton X-100 treated $1 \times \mathrm{PBS}, 14 \mu \mathrm{L}$ ) without the N-protein. Apply $15 \mu \mathrm{L}$ of the positive and negative control solutions to assembled vertical flow assays and wash with the washing buffer ( $200 \mathrm{mM}$ phosphate $\mathrm{pH} 6$ buffer including $150 \mathrm{mM} \mathrm{NaCl}, 5 \mathrm{w} / \mathrm{v} \% \mathrm{BSA}$, and $0-1 \mathrm{v} / \mathrm{v} \%$ detergents, $50 \mu \mathrm{L}$ ). Flip the devices, remove wicking pads, and add $10 \mu \mathrm{L}$ of TMB substrate solution. Image the test zones after 2-min color development. 


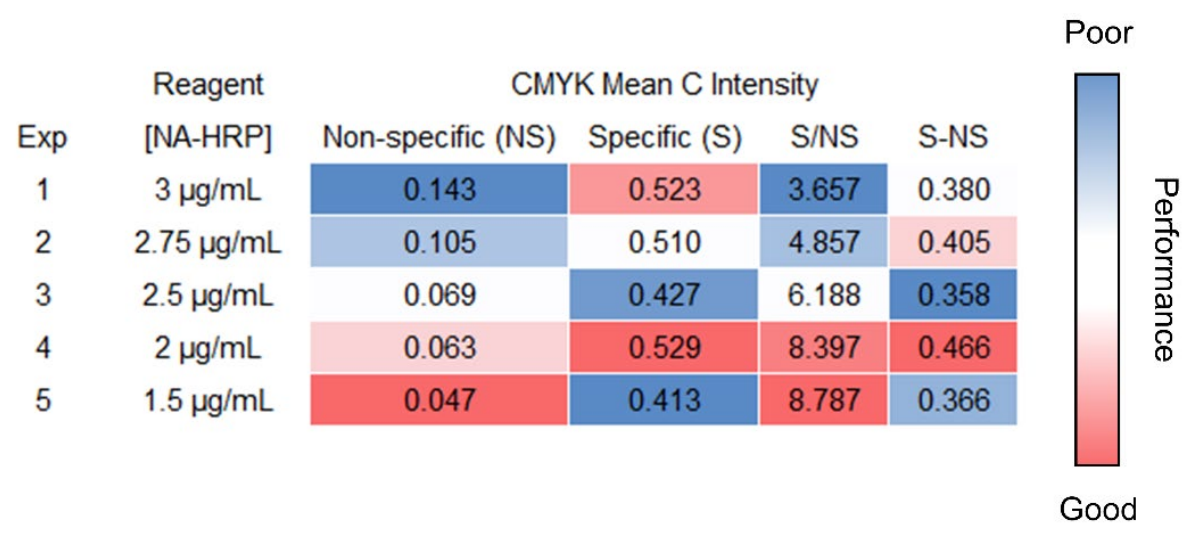

Figure S15. Optimization of simulated swab assays - enzyme concentration. Paper-based assays are prepared by pre-immobilizing SsoNP.E2-CBD $(30 \mu \mathrm{M}, 0.5 \mu \mathrm{L})$ on test zones on the fourth layer and blocking all wells with $0.5 \mathrm{w} / \mathrm{v} \%$ casein blocker $5 \mathrm{w} / \mathrm{v} \%$ sucrose $0.1 \mathrm{v} / \mathrm{v} \%$ Tween-20 $150 \mathrm{mM} \mathrm{NaCl}$ in $0.1 \mathrm{M}$ phosphate buffer ( $\mathrm{pH}$ 6.3) $(1 \mu \mathrm{L})$. The condition $4(2 \mu \mathrm{g} / \mathrm{mL}$ neutravidin-HRP in reagent solution) provided relatively high S/NS and S-NS simultaneously, so we decided to use the condition 4 for the enzyme concentration.

Protocol (variable for optimization and range highlighted in red): Freshly prepare reagent solution including $750 \mathrm{nM}$ BA-MBP-SsoNP.E1 and 1.5-3 $\mu \mathrm{g} / \mathrm{mL}$ neutravidin-HRP in $\mathrm{pH} 6$ diluent (150 mM phosphate buffer). Add the prepared reagent solution $(1 \mu \mathrm{L})$ to positive simulated swab sample $(1 \mathrm{v} / \mathrm{v} \%$ Triton X-100 treated $1 \times$ PBS, $14 \mu \mathrm{L}$ ) including $5 \mathrm{nM}$ SARS-CoV-2 N-protein and negative simulated swab sample (1 v/v \% Triton X-100 treated $1 \times \mathrm{PBS}, 14 \mu \mathrm{L}$ ) without the N-protein. Apply $15 \mu \mathrm{L}$ of the positive and negative control solutions to assembled vertical flow assays and wash with the washing buffer (200 $\mathrm{mM}$ phosphate pH 6 buffer including $150 \mathrm{mM} \mathrm{NaCl}, 5 \mathrm{w} / \mathrm{v} \% \mathrm{BSA}$, and $1 \mathrm{w} / \mathrm{v} \% \mathrm{CHAPS}, 50 \mu \mathrm{L}$ ). Flip the devices, remove wicking pads, and add $10 \mu \mathrm{L}$ of TMB substrate solution. Image the test zones after 2-min color development. 
(A) Nucleocapsid protein concentration (nM) in saliva

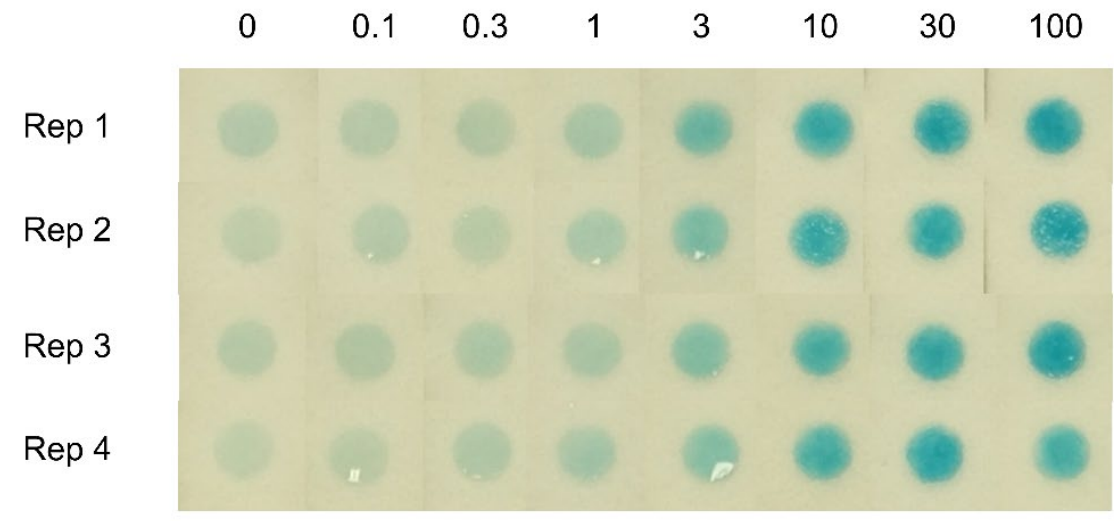

(B) Nucleocapsid protein concentration (nM) in 1×PBS

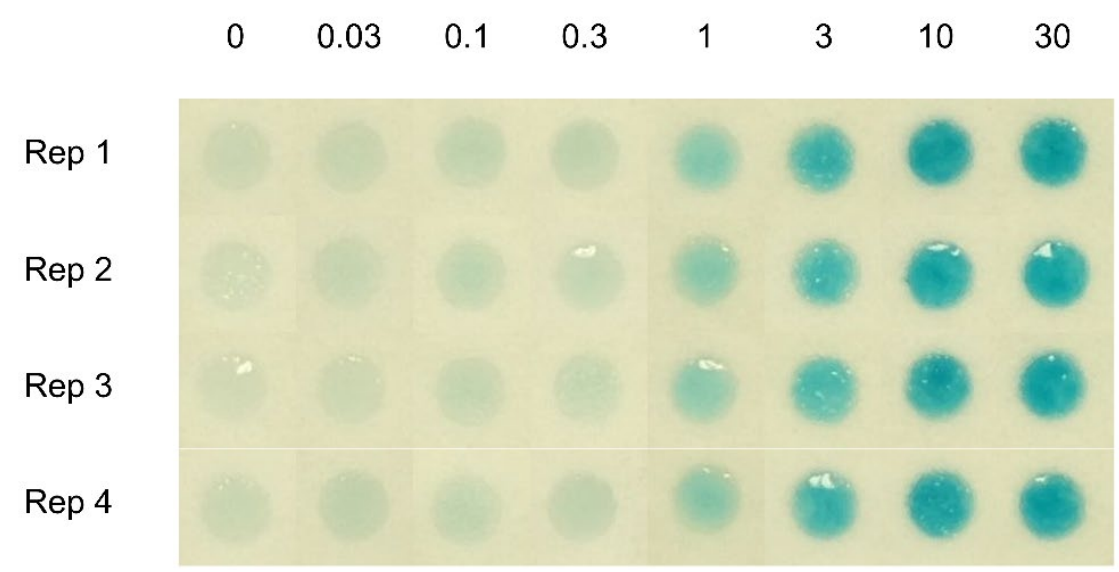

Figure S16. Images of the assay results with recombinant SARS-CoV-2 N-protein spiked into (A) saliva and (B) $1 \times$ PBS. 
(A) SARS-CoV-2 concentration $\left(\times 10^{3} \mathrm{PFU} / \mathrm{mL}\right)$ in saliva

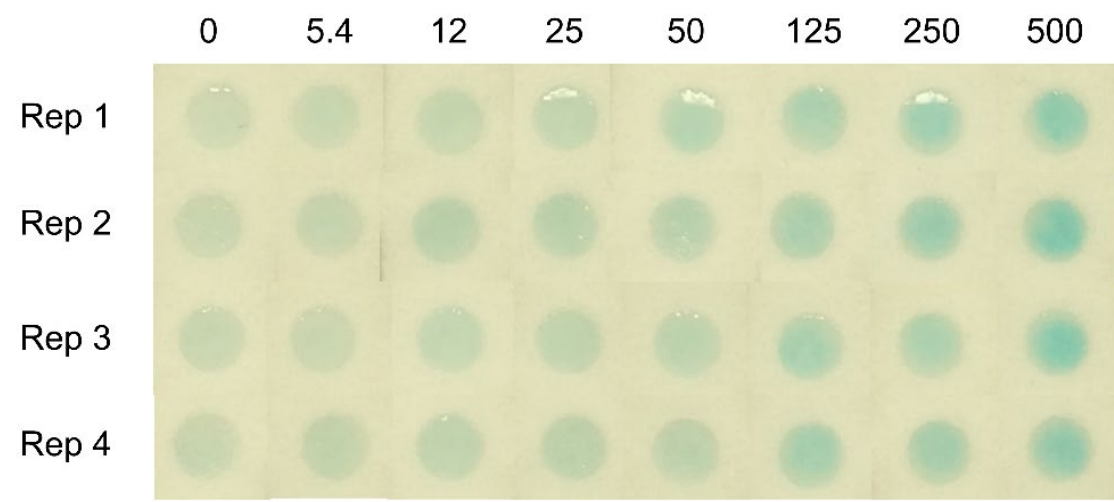

(B) SARS-CoV-2 concentration $\left(\times 10^{3} \mathrm{PFU} / \mathrm{mL}\right)$ in $1 \times \mathrm{PBS}$

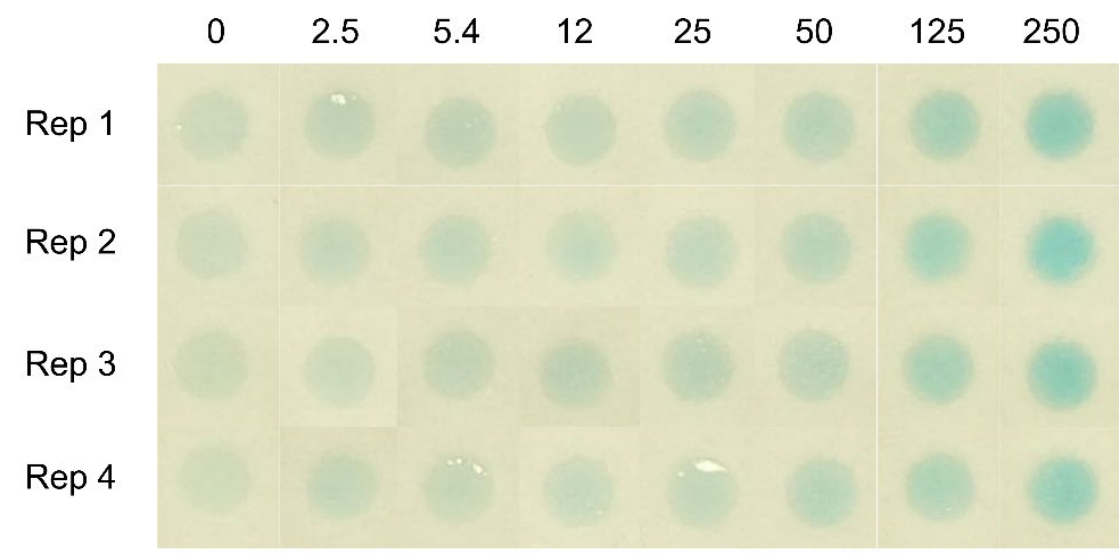

Figure S17. Images of the assay results with cultured SARS-CoV-2 spiked into (A) saliva and (B) $1 \times$ PBS. 
(A)

$\mathrm{N}$-protein in 1XPBS

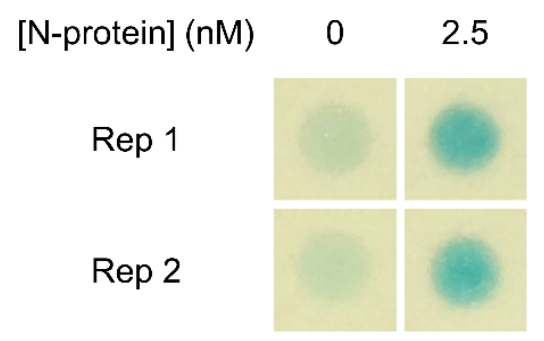

(B)

$\mathrm{N}$-protein in swab matrix

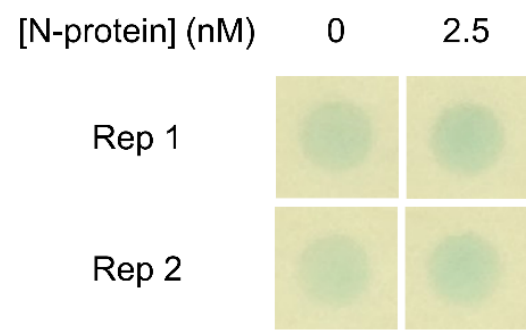

Figure S18. Effect of swab matrix on SARS-CoV-2 N-protein detection in vertical flow assays. With assay conditions optimized for N-protein detection in $1 \times \mathrm{PBS}$, specific signals are drastically reduced when $\mathrm{N}$ protein is spiked into nasopharyngeal swab matrix.

\section{References}

(1) https://www.ncbi.nlm.nih.gov/protein/YP_009724397 (Last accessed on 04/12/2021).

(2) Sung, K. J.; Miller, E. A.; Sikes, H. D. Engineering Hyperthermostable rcSso7d as Reporter Molecule for in Vitro Diagnostic Tests. Mol. Syst. Des. Eng. 2018, 3 (6), 877-882.

(3) Miller, E. A.; Baniya, S.; Osorio, D.; Maalouf, Y. J. Al; Sikes, H. D. Paper-Based Diagnostics in the Antigen-Depletion Regime: High-Density Immobilization of rcSso7d-Cellulose-Binding Domain Fusion Proteins for Efficient Target Capture. Biosens. Bioelectron. 2018, 102, 456-463.

(4) Miller, E. A.; Sung, K.; Kongsuphol, P.; Baniya, S.; Aw-yong, H. Q.; Tay, V.; Tan, Y.; Kabir, F. M.; Pang-yeo, K.; Kaspriskie, I. G.; Sikes, H. D. Beyond Epitope Binning: Directed in Vitro Selection of Complementary Pairs of Binding Proteins. ACS Comb. Sci. 2020, 22, 49-60.

(5) Dutta, N. K.; Mazumdar, K.; Gordy, J. T. The Nucleocapsid Protein of SARS-CoV-2: A Target for Vaccine Development. J. Virol. 2020, 94 (13), e 00647-20.

(6) Welch, S. R.; Davies, K. A.; Buczkowski, H.; Hettiarachchi, N.; Green, N.; Arnold, U.; Jones, M.; Hannah, M. J.; Evans, R.; Burton, C.; Burton, J. E.; Guiver, M.; Cane, P. A.; Woodford, N.; Bruce, C. B.; Roberts, A. D. G.; Killip, M. J. Analysis of Inactivation of SARS-CoV-2 by Specimen Transport Media, Nucleic Acid Extraction Reagents, Detergents, and Fixatives. J. Clin. Microbiol. 2020, 58 (11), e01713-e01720.

(7) Chen, Y.; Zhong, Q.; Wang, Y.; Yuan, C.; Qin, X.; Xu, Y. Colorimetric Detection of Hydrogen Peroxide and Glucose by Exploiting the Peroxidase-like Activity of Papain. RSC Adv. 2019, 9, $16566-16570$.

(8) Shan, D.; Johnson, J. M.; Fernandes, S. C.; Suib, H.; Hwang, S.; Wuelfing, D.; Mendes, M.; Holdridge, M.; Burke, E. M.; Beauregard, K.; Zhang, Y.; Cleary, M.; Xu, S.; Yao, X.; Patel, P.; Plavina, T.; Wilson, D.; Chang, L.; Kaiser, K. M.; Natterman, J.; Schmidt, S. V.; Latz, E.; Hrusovsky, K.; Mattoon, D.; Ball, A. J. N-Protein Presents Early in Blood, Dried Blood and Saliva during Asymptomatic and Symptomatic SARS-CoV-2 Infection. Nat. Commun. 2021, 12, 1931. 